\title{
Application of Fe-Based Amorphous Alloy in Industrial Wastewater Treatment: A Review
}

\author{
Liefei Pei, Xiangyun Zhang and Zizhou Yuan \\ School of Materials Science and Engineering, Lanzhou University of Technology, Lanzhou, 730050, China \\ *Corresponding Author: Zizhou Yuan. Email: yuanzz@lut.cn
}

Received: 25 May 2021 Accepted: 23 July 2021

\begin{abstract}
Amorphous alloy (MGs) is a solid alloy with disordered atomic accumulation obtained by ultra-rapid solidification of alloy melt. The atom deviates from the equilibrium position and is in metastable state. Up to now, a large number of MGs have been applied to the treatment of dye and heavy metal contaminated wastewater and ideal experimental results have been obtained. However, there is no literature to systematically summarize the chemical reaction and degradation mechanism in the process of degradation. On the basis of reviewing the classification, application, and synthesis of MGs, this paper introduces in detail the chemical reactions such as decolorization, mineralization, and ion leaching of Fe-based amorphous alloy (Fe-MGs) in the degradation of organic and inorganic salt wastewater through direct reduction or advanced oxidation mechanism. Compared with crystalline materials, the higher reaction rate of Fe-MGs can be attributed to lower activation energy, negative redox potential, loose product layer, and band structure with downward shift of valence band top. Finally, some suggestions and prospects are put forward for the limitations and research prospects of MGs in the environmental field, which provides a new idea for the synthesis of new environmental functional materials.
\end{abstract}

\section{KEYWORDS}

Amorphous alloy; industrial waste water; direct reduction; advanced oxidation; reaction activity

\section{Introduction}

The problem of environmental pollution has perplexed the development of human society since the industrial revolution, so researchers have never stopped exploring the development and utilization of environmental functional materials. Environmental functional materials are new materials that specifically remove harmful substances according to the types and properties of pollutants in the environment. They have the advantages of high reactive activity, low energy consumption, high repetitive utilization rate, little ecological impact, and even has the function of improving and regulating ecological balance [1]. When this kind of material is applied to the treatment of industrial wastewater, it can effectively reduce the treatment cost, save natural resources, and reduce the secondary pollution to the environment. At present, common environmental functional materials can be divided into the following three categories [2]: (1) Production waste. For example, steel slag, fly ash and iron filings in industrial production, and biochar materials prepared from potato slag, rice husk, and straw in agricultural production. (2) Natural minerals. Bentonite, red clay, and attapulgite, etc. (3) Nanomaterials. Nano-sized zero-valent iron, carbon 
nanotubes, graphene, and carbon-supported nano- $\mathrm{TiO}_{2}$ and so on. Among them, production waste and natural minerals are the main parts of traditional environmental functional materials, although the cost is low, but there are some shortcomings such as poor treatment effect and low recycling utilization. Therefore, researchers try to find new materials with low production cost and high reaction activity from other functional materials.

MGs (Fig. 1) is a solid alloy with disordered atomic packing structure, which is obtained when the atoms of the alloy melt are not arranged and crystallized in time during rapid solidification. The internal microparticle arrangement is not periodic, and there is no grain and grain boundary of the crystalline alloy. Compared with the crystalline alloy with regular arrangement of atoms, MGs is a complex structure of many-body interaction. The reason is the particularity of atomic and electronic structure, the whole system is in a thermodynamically metastable state and has higher Gibbs free energy [3]. This special structure makes it have the following properties different from traditional alloy materials: (1) Mechanical properties. Compared with ordinary crystalline alloys, amorphous alloys have no microstructure defects during solidification, so the bonding between atoms is stronger than that of crystalline alloys. In addition, the atoms arranged uniformly and closely together make the amorphous alloy not easy to slip under stress. These factors make the amorphous alloy have good mechanical properties and can be regarded as one of the structural materials with the highest strength. The Co-Fe-Ta-B bulk amorphous alloy developed by Inoue et al. [4] is the metal material with the highest strength at present, and its compressive strength reaches $5185 \mathrm{MPa}$. (2) Magnetic properties. MGs have a higher saturation magnetic induction compared to their crystalline counterparts. Therefore, their soft magnetic properties are better than those of traditional magnetic materials such as silicon steel, ferrite, and Fe-Ni alloy. The application of MGs to transformers can greatly improve the efficiency, reduce the volume, reduce the weight, and reduce the energy consumption of transformers. At present, there are three kinds of mature amorphous soft magnetic alloys: Fe-based, Co-based, and Fe-Ni-based. They all have excellent soft magnetic properties and can be widely used in the field of power electronics as high-frequency transformers, sensors, and chokes. (3) Electrical properties. Due to the addition of metal-like elements and the chaotic arrangement of atoms, MGs have a strong ability to scatter electrons. At room temperature, the resistivity of MGs is about 100-300 $\mu \Omega \cdot \mathrm{cm}$, while the resistivity of the crystalline alloy with the same composition is $1 / 3-1 / 2$ times lower than that of the same composition [5]. Based on the above excellent properties, MGs have become a new functional material with great research value.

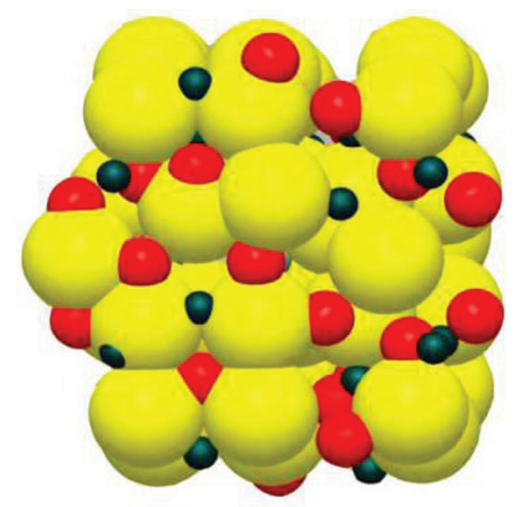

Figure 1: Schematic diagram of MGs structure

In the early 1980s, MGs began to be used in the field of catalysis [6]. In recent years, researchers have carried out a large number of applied and theoretical studies on the catalytic degradation of environmental pollutants by MGs. In the experiment of treating dye wastewater, it is found that MGs have higher reaction 
rate and degradation rate than crystalline alloy [7]. The results of theoretical analysis show that MGs with abundant active sites, which can be attributed to the crystal structure dislocations, distortions, and impurities such as metals and metal-like elements caused by the accumulation of disordered atoms [8]. Secondly, the single-phase property of MGs is conducive to the uniform dispersion of reactants on its surface, forming a chemically homogeneous environment, and the high reaction activity is also attributed to the high concentration of unsaturated coordination atoms on the surface [9]. In addition, the element composition and atomic ratio of MGs can be widely adjusted according to the nature of pollutants and treatment environment [10]. Common MGs in the field of water treatment can be divided into the following categories: (1) The most widely used Fe-MGs [11]. Fe have the advantages of non-toxic, rich, cheap, and spontaneous reduction process, so it is an effective reducing agent in the removal of oxidizing pollutants. Single element iron can not form amorphous structure. In order to improve the glass forming ability and thermal stability, a small amount of other metals or metal-like elements are added to Fe to form alloys, such as Fe-B, Fe-Si-B, Fe-Si-B-P and so on. These elements have the advantages of low price and little harm to the environment, which reduce the redox potential of Fe-MGs to a certain extent and promote the catalytic degradation reaction. Based on the above advantages, Fe-MGs is the most widely used MGs in water treatment. (2) Aluminum-based amorphous alloy (Al-MGs) [12] and magnesium-based amorphous alloy (Mg-MGs) [13] with strong reducibility. Because the standard redox potentials of $\mathrm{Al}$ and $\mathrm{Mg}$ are $-1.66 \mathrm{~V}$ and $-2.37 \mathrm{~V}$, respectively, they show higher reaction activity than $\mathrm{Fe}-\mathrm{MGs}$ in the reaction with pollutants. However, the price of the main elements $\mathrm{Al}$ and $\mathrm{Mg}$ is much higher than that of Fe, which is limited in large quantities of water treatment applications. (3) Copperbased amorphous alloy (Cu-MGs) [14] and nickel-based amorphous alloy (Ni-MGs) [15] with low metal leaching rate. Although the catalytic activity of this kind of MGs is lower than that of the former two types, it contains $\mathrm{Cu}$ and $\mathrm{Ni}$, which reduces the metal leaching rate in the reaction process and reduces the secondary pollution to the water body, which also has research and application value.

This paper collates the literature on the application of iron-based amorphous alloy (Fe-MGs) in the field of industrial wastewater treatment. The chemical reactions occurred in the treatment of wastewater polluted by organic and inorganic salts by Fe-MGs are analyzed systematically. The two degradation mechanisms of direct reduction and advanced oxidation are discussed emphatically. Finally, some reasonable prospects and suggestions are put forward according to the limitations of MGs in the field of environment.

\section{Preparation Method of MGs}

Since Au-Si amorphous alloy was first prepared by melt quenching method by Klement et al. [16] in 1960, researchers have developed a series of preparation processes of MGs. The remarkable difference between MGs and crystalline alloy lies in the randomness of atomic arrangement. In the cooling stage of alloy preparation, the atoms will be arranged spontaneously from a disordered state to a periodic crystal structure [17]. In the production of MGs, in order to hinder the regular arrangement of atoms into crystals, the commonly used processes include rapid cooling, mechanical alloying, inhibition of nucleation, zone melting, and chemical reduction.

\subsection{Rapid Cooling}

The rapid cooling technology is to transfer the heat of the melt to the cooling medium quickly through the contact between the high temperature melt and the low temperature and high thermal conductivity medium, so as to achieve the purpose of cooling the alloy melt very rapidly. the commonly used methods are single roll strip casting, copper mold casting, and gas atomization.

\subsubsection{Single Roll Strip Casting}

Single roll strip casting is the main method to prepare strip MGs. The structure of the single roll strip casting machine is shown in Fig. 2. When the high frequency current flows through the water-cooled 
copper tube coil made into a ring, there is a strong magnetic beam with instantaneous polarity change, which will run through the whole alloy to be heated, thus inducing a strong eddy current. Due to the existence of alloy resistance will produce Joule heat, so that the alloy temperature rises rapidly to melt. By controlling the pressure difference inside and outside the quartz tube, the melt is sprayed into a high-speed rotating copper roller or mold, thus the preparation of a non-equilibrium ribbon with a thickness of 10-70 $\mu \mathrm{m}$ is realized $[18,19]$. The technology of single-roll strip spinning has been fully mature and industrial production has been realized, especially the Fe-MGs produced by this method is the main raw material of amorphous core in transformer [20]. At the same time, it also provides a material guarantee for the application of MGs as an environmental functional material in the field of catalytic degradation.

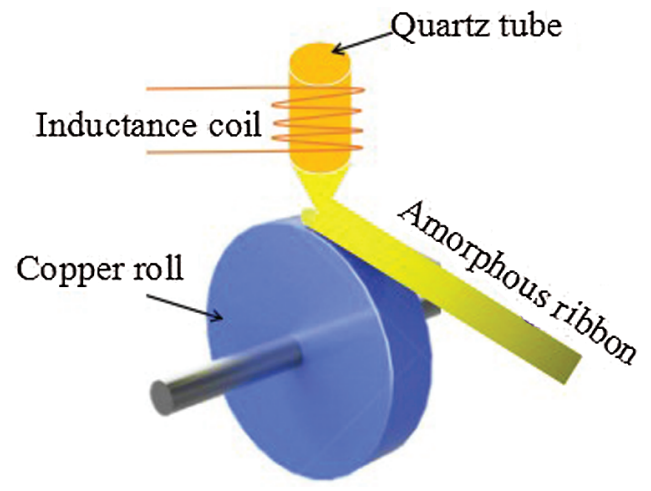

Figure 2: Process flow chart of single roll strip casting

\subsubsection{Copper Mold Casting}

The size of MGs is limited by the ability of amorphous forming. Copper mold casting is usually used to produce bulk MGs with strong amorphous forming ability. As shown in Fig. 3, the master alloy is heated by an induction coil to make it melt in the quartz tube. Then in an inert atmosphere, the molten alloy liquid is injected into copper by means of blow casting, suction casting and extrusion. Because of the high thermal conductivity of the copper mold, the melt can be cooled quickly, and the bulk amorphous alloy is prepared [21]. In order to make the melt cool quickly in a short time, the volume of the copper mold should be large enough. The copper mold can be water-cooled or not water-cooled. The shapes of copper molds can be divided into wedge-shaped, trapezoidal, rod-shaped and square-shaped. The advantage of copper mold casting is that it is easy to operate and can prepare bulk amorphous alloys of various shapes. The disadvantage is that when the copper mold is used for cooling, the cooling rate is limited $\left(10-10^{3} \mathrm{~K} / \mathrm{s}\right)$, and the size of the prepared bulk amorphous alloy is usually small, so it is difficult to achieve large-scale and industrial production. Generally, it is mostly used for laboratory research [22].

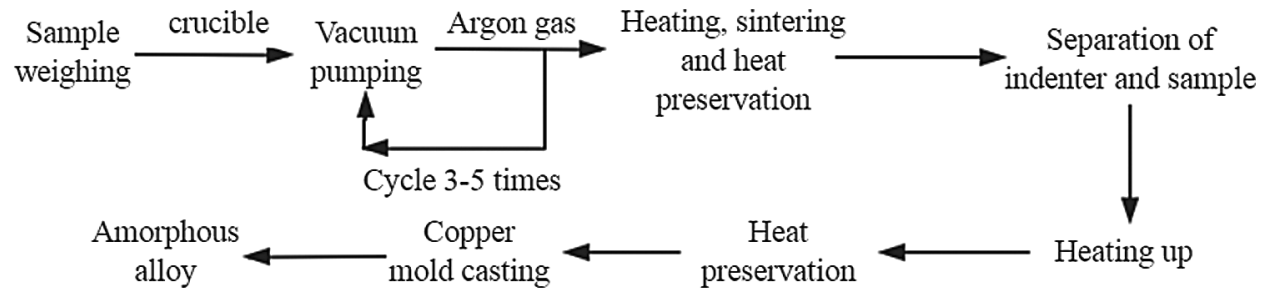

Figure 3: Process flow chart of copper mold casting 


\subsubsection{Gas Atomization Method}

According to the different atomization medium used, the atomization powders are divided into air atomization and water atomization, which is mainly used to prepare fine powder MGs. The preparation process is that the liquid metal is sheared by high-speed air flow or water flow in the atomization chamber, the kinetic energy of the atomized medium is converted into the surface energy of the liquid metal, and the liquid metal is divided into micron droplets. The process is shown in Fig. 4. The amorphous structure is formed because the droplet size is small and it is easy to obtain a higher cooling rate during the cooling process [23,24]. Chang et al. [25] compared the properties of $\mathrm{Fe}_{76} \mathrm{Si}_{9} \mathrm{~B}_{10} \mathrm{P}_{5} \mathrm{Fe}-$ based amorphous alloy powders prepared by water atomization and gas atomization. The results show that the composition of the powders prepared by the two methods is uniform and the amorphous structure is obvious. Compared with the gas atomized powders, the water atomized powders are more dispersed and the sphere are more regular. The saturation magnetization of the two kinds of amorphous powders are similar, but the coercivity of water atomized powders are lower. The above results show that the performance of $\mathrm{Fe}_{76} \mathrm{Si}_{9} \mathrm{~B}_{10} \mathrm{P}_{5}$ amorphous powders prepared by water atomization method are better than that of gas atomization powders. Compared with ribbon and block MGs, powdered MGs have higher specific surface area in the reaction with pollutants. However, the whole process of atomization is a very complex physical and chemical process, and there is little theoretical guidance in this field. Moreover, the long time interval of nebulizer replacement, the non-uniform design standard, and the high research cost restrict its development in the metal powder production industry. In recent years, with the continuous improvement of the production process of liquid metal pneumatic atomization, coupled with the further study of the mechanism of gas atomization, the technology of metal pneumatic atomization will be continuously improved.

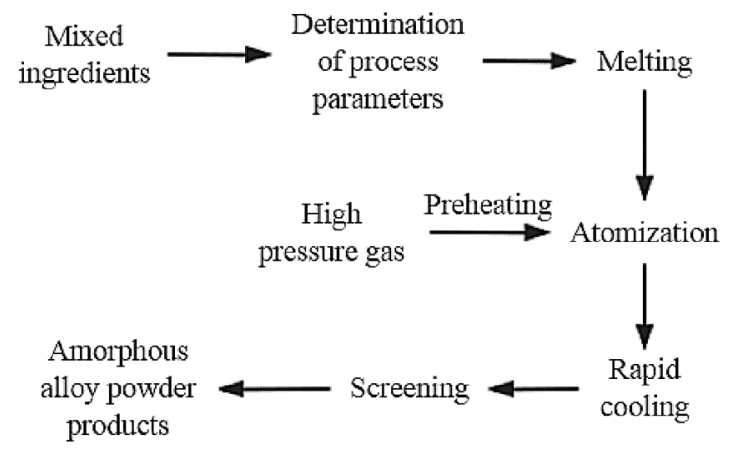

Figure 4: Process flow chart of gas atomization

\subsection{Mechanical Alloying}

The method of preparing MGs by mechanical alloying is to make the material deform, break and cold weld repeatedly through the collision and friction between the alloyed material and the hard steel ball in the high energy ball mill for a long time, so as to improve the atomic mobility and dislocation density at the interface of the material until the crystal structure is completely lost (Fig. 5). The ball-milled powders have rough surface, irregular shape, larger specific surface area and higher catalytic efficiency than atomized powders [26,27]. In addition, the residual stress in the ball-milled powders will lead to the increase of free energy, thus further improving the catalytic activity [28]. In order to obtain amorphous powders with small particle size and rough surface, the researchers combined gas atomization method with mechanical alloying method. For example, Surreddi et al. [29] first prepared $\mathrm{Al}_{84} \mathrm{Gd}_{6} \mathrm{Ni}_{7} \mathrm{Co}_{3}$ amorphous powders by gas atomization method, and then the powders were milled for different time. It is

found that the original crystal phase is amorphized. At the same time, the regular spherical structure 
disappears and presents an irregular rough surface. With the extension of ball milling time, the initial crystallization temperature of amorphous increases while the crystallization temperature of intermetallic phase decreases, and the hardness of the powders increase obviously. The production of MGs by mechanical alloying has the advantages of simple technological process, low equipment requirements, and high yield. The disadvantage is that the production cycle is long, the loss of equipment is serious, and the output is small. Therefore, it is not suitable for industrial production and is mainly used for laboratory research.

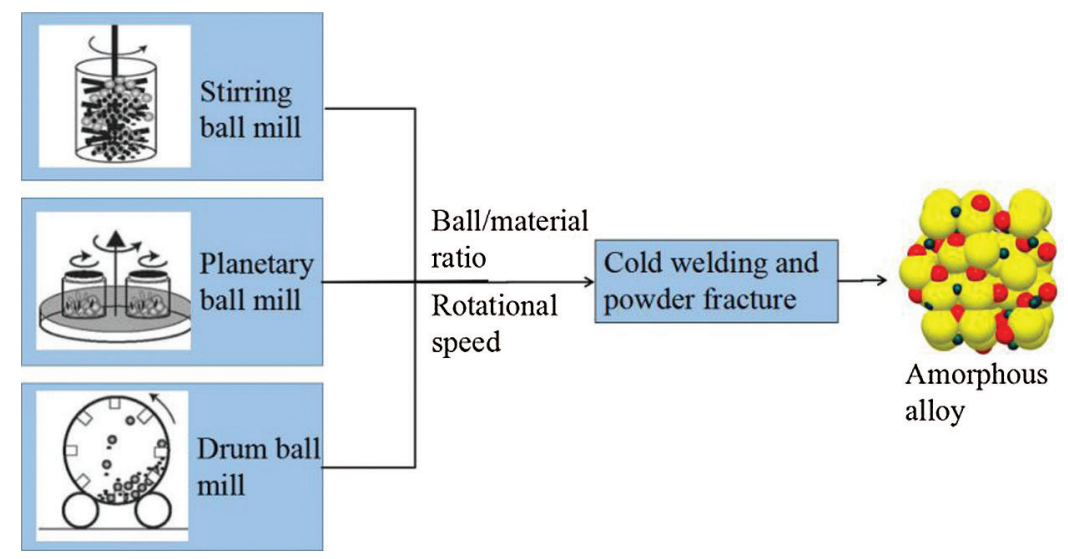

Figure 5: Schematic diagram of mechanical alloying

\subsection{Inhibition of Nucleation}

The inhibition of nucleation is mainly the inhibition of heterogeneous nucleation. In the alloy design and equipment selection, attention should be paid to improving the purity of the material, doping the secondary elements which are quite different from the atomic size of the main elements, and the crystal structure of the selected cooling medium is quite different from that of the crystal nucleus [30]. The commonly used methods are tube drop method, molten glass purification method and suspension melting method [31]. These methods are to reduce the contact between the melt and the container in the cooling process, avoid heterogeneous nucleation and improve the amorphous forming ability of the material.

\subsection{Zone Melting}

The above methods are all segmented operation, and the material size is small, so it is not suitable for the production of large parts and materials. For this reason, the zone melting technology (Fig. 6) is developed to produce rod-like MGs. The rod-like alloy material is placed in the groove of water-cooled copper die, and the material is melted by high-energy heat source. At the same time, the relative motion between the copper mold and the heat source causes the rapid movement of the solid-liquid interface. The huge temperature gradient between the melting zone and the solid zone rapidly cools the melting zone to form an amorphous structure [32]. This process has been widely used in industrial production. The size of rod-shaped MGs prepared by this process can reach $200 \times 10 \times 10 \mathrm{~mm}$.

\subsection{Chemical Reduction Method}

The chemical reduction method is to use the reducing agent containing metal-like metal $\left(\mathrm{KBH}_{4}\right.$ or $\mathrm{NaH}_{2} \mathrm{PO}_{2}$ ) to drop into the metal salt solution, so that the metal ion is reduced to metal, and then the metal particles are repeatedly leached and dried to obtain nano-sized amorphous particles. The preparation parameters such as $\mathrm{pH}$ value of solution, metal elements, ratio of reactants and temperature have important effects on the microstructure and catalytic performance of MGs. Compared with other 
processes mentioned above, the preparation conditions of the chemical reduction method are mild, the morphology of the nanoparticles can be controlled and the composition of the alloy is not limited by the eutectic composition, and the atomic ratio can be changed arbitrarily [33]. This method has been widely used in the production of nanometer amorphous catalysts.

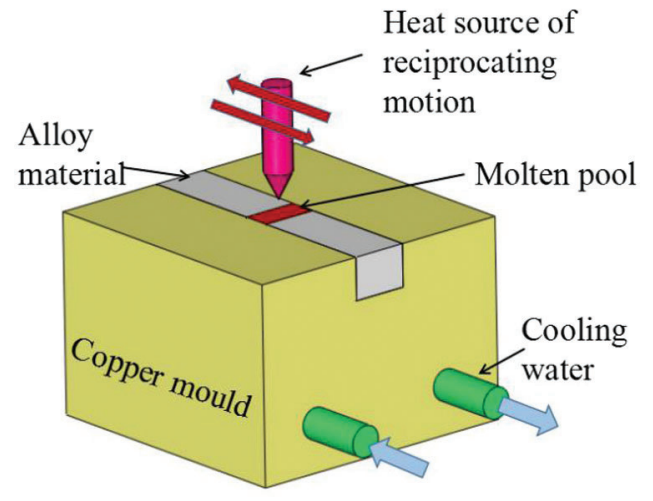

Figure 6: Schematic diagram of zone melting method

\section{Treatment of Dye Wastewater by MGs}

In recent years, the annual output of the global synthetic dye market has exceeded 10 million tons and continues to grow at a rate of 3-4\%. At the same time, the production and use of dyes are accompanied by energy consumption and environmental pollution. According to the investigation, about $744 \mathrm{~L}$ of waste water is discharged to the environment for each production of $1 \mathrm{~kg}$ synthetic dyes [34,35]. Dyeing $1 \mathrm{~kg}$ cotton requires $30-60 \mathrm{~g}$ dyes and $70-150 \mathrm{~L}$ water, of which $10-20 \%$ of the dyes are indirectly released into the environment because they cannot be fully utilized [36]. The dyes are mainly composed of polyphenylene ring substituted compounds and heavy metal salts such as lead, arsenic, chromium, mercury and so on. Once this kind of highly toxic, high chromaticity and refractory substances enter the water ecosystem, it will cause serious damage to the ecological balance. Therefore, the reasonable treatment of dye wastewater can not only reduce the harm to the environment and protect human health, but also reuse the purified water and save limited water resources, which is in line with the sustainable development strategy advocated all over the world.

\subsection{Decolorization Reaction}

The ability of dyes to show different colors is based on the conjugated systems such as azo bond and nitrogen-oxygen bond in dye molecules. When visible light is irradiated on the dye, the conjugated system can selectively absorb specific wavelength energy. The light in other bands is reflected and presents different colors [37]. The decolorization reaction of MGs with organic dyes is to destroy the chromophoric groups such as $\mathrm{C}=\mathrm{O},-\mathrm{N}=\mathrm{N}-,-\mathrm{NO}_{2}$, and $-\mathrm{N}=\mathrm{O}$, which can be used as chromogenic groups. The results show that the chromaticity removal rate of MGs for commonly used dye-contaminated wastewater is close to $100 \%$. For example, Jia et al. [38] developed a multi-component $\mathrm{Fe}_{83} \mathrm{Si}_{2} \mathrm{~B}_{11} \mathrm{P}_{3} \mathrm{C}_{1} \mathrm{AR}^{\mathrm{AR}}$ catalyst using arc melting and melt spinning technology to treat mixed aqueous solutions containing rhodamine B, methylene blue, methyl orange, and complex organic structures. As shown in Fig. 7, the solution is gradually decolorized to colorless within $30 \mathrm{~min}$. The decolorization rate of the above four different organic wastewater is $100 \%$. By comparing the degradation rates of the three dyes, it is found that the degradation rate of methylene blue with amino group by $\mathrm{Fe}_{83} \mathrm{Si}_{2} \mathrm{~B}_{11} \mathrm{P}_{3} \mathrm{C}_{1}{ }^{\mathrm{AR}}$ is the fastest, methyl orange with azo bond as chromophore is the second, and rhodamine $\mathrm{B}$ with phenylamino group and carbonyl group as chromophore is the slowest. This shows that the different functional groups in the dyes 
have a direct effect on the decolorization reaction. Xie et al. [39] compared the decolorization performance of methyl orange wastewater by $\mathrm{Fe}_{76} \mathrm{~B}_{12} \mathrm{Si}_{9} \mathrm{Y}_{3}{ }^{\mathrm{AR}}$ and crystalline zero-valent iron (ZVI). After $1 \mathrm{~h}$, the wastewater treated by $\mathrm{Fe}_{76} \mathrm{~B}_{12} \mathrm{Si}_{9} \mathrm{Y}_{3}{ }^{\mathrm{AR}}$ lost color completely, while the wastewater treated by ZVI still had high chromaticity. In order to understand the degradation process, the mass spectrometric analysis of the intermediate products is shown in Fig. 8. Methyl orange is first decomposed into N-dimethylaniline, $\mathrm{N}$-dimethyl-p-phenylenediamine, and sulfonamide, followed by further degradation into small molecular organic compounds such as benzenesulfonic acid, and partially decomposed into carbon dioxide and water. The authors believe that the excellent properties of $\mathrm{Fe}_{76} \mathrm{~B}_{12} \mathrm{Si}_{9} \mathrm{Y}_{3}{ }^{\mathrm{AR}}$ are mainly due to the heterogeneous structure composed of local iron-rich and poor iron clusters, rather than the large specific surface area and strong residual stress of the powders. Table 1 shows the decolorization rate of some MGs to dye wastewater.

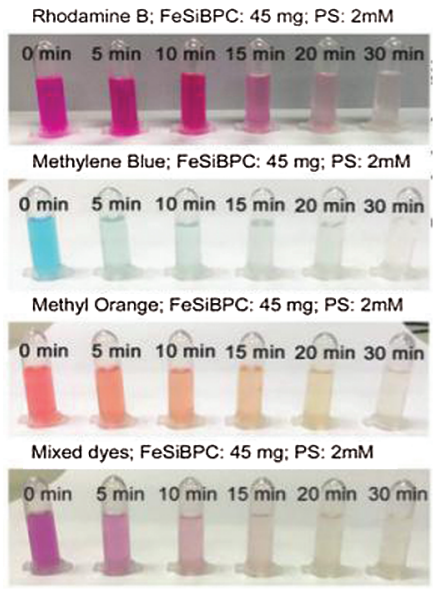

(a)

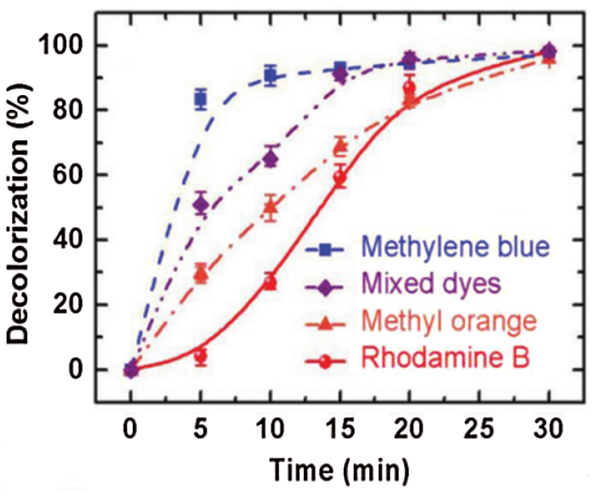

(b)

Figure 7: The color change (a) and decolorization rate (b) of rhodamine $\mathrm{B}$, methylene blue, methyl orange and mixed dyes degraded by $\mathrm{Fe}_{83} \mathrm{Si}_{2} \mathrm{~B}_{11} \mathrm{P}_{3} \mathrm{C}_{1}{ }^{\mathrm{AR}}$ [38]

\subsection{Mineralization Reaction}

The chromaticity of dyes can reflect the content of dyes in solution to a certain extent, but the decrease of chromaticity does not prove that dyes are completely decomposed, only that the chromophoric groups in dye molecules are destroyed [47]. In order to more accurately reflect the performance of MGs in the degradation of dyes, the researchers proposed to use organic carbon content (TOC) to measure the degree of mineralization of polymer dyes into small molecules such as $\mathrm{CO}_{2}, \mathrm{H}_{2} \mathrm{O}$, and inorganic salts [48]. Jia et al. [49] used $\mathrm{Fe}_{78} \mathrm{Si}_{9} \mathrm{~B}_{13}{ }^{\mathrm{AR}}$ to treat brilliant red $3 \mathrm{~B}-\mathrm{A}$ solution, most of the dyes can be degraded into inorganic salts such as $\mathrm{H}_{2} \mathrm{O}, \mathrm{CO}_{2}, \mathrm{NO}_{3}{ }^{-}$, and $\mathrm{SO}_{4}{ }^{2-}$ within $5 \mathrm{~min}$, and the final removal rate of TOC can reach $80 \%$. However, due to the existence of $\mathrm{Cu}$ and $\mathrm{Nb}, \mathrm{Fe}_{73.5} \mathrm{Si}_{13.5} \mathrm{~B}_{9} \mathrm{Cu}_{1} \mathrm{Nb}_{3}{ }^{\mathrm{AR}}$ is difficult to form pores on the surface of the strip, so the reaction activity is reduced, the reaction time is extended to $30 \mathrm{~min}$, and the removal rate of TOC is reduced to $65 \%$. Table 2 lists several MGs removal rates of TOC in dye wastewater.

\subsection{Leaching Reaction}

Ions are inevitably released into the water during the reaction between MGs and pollutants, which not only causes secondary pollution to the environment, but also reduces the recycling utilization of the catalyst. There are two main sources of leaching ions: (1) After the molecular structure of the dye is destroyed, the 
metal ions contained in it break away from the bulk structure and enter into the solution. (2) The redox reaction occurs between MGs and dyes, and part of MGs loses electrons and is leached in solution. It is difficult to reduce the amount of ions released from dye molecules in the process of degradation, so it is necessary to reasonably design the structure and composition of MGs to reduce the leaching of catalysts. On the one hand, choose metals and metal-like elements that have no pollution to the environment, such as $\mathrm{Fe}, \mathrm{Si}, \mathrm{B}$ and so on. On the other hand, corrosion resistant elements such as $\mathrm{Ni}, \mathrm{Nb}$ are added to it. In order to reduce the leaching rate of MGs, Liang et al. [51] doped 3\% $\mathrm{Nb}$ into the alloy, the initial dosage of $\mathrm{Fe}_{73.5} \mathrm{Si}_{13.5} \mathrm{~B}_{9} \mathrm{Cu}_{1} \mathrm{Nb}_{3}{ }^{\mathrm{AR}}$ was $2 \mathrm{~g} / \mathrm{L}$, and the leaching amounts of $\mathrm{Fe}$ and $\mathrm{Si}$ after reaction with malachite green are $28 \mathrm{mg} / \mathrm{L}$ and $0.05 \mathrm{mg} / \mathrm{L}$, respectively. Wang et al. [53] obtained that the leaching amount of $\mathrm{Fe}$ after the degradation of methylene blue by $\mathrm{Fe}_{78} \mathrm{Si}_{9} \mathrm{~B}_{13}{ }^{\mathrm{AR}}$ is only $26 \mathrm{mg} / \mathrm{L}$, and the $\mathrm{SiO}_{2}$ attached to the surface of the strip after the reaction played a role in reducing the leaching of the catalyst to a certain extent. Some scholars believe that the proper leaching of non-toxic ions can improve the electrical conductivity of the solution and promote the electron transfer on the interface of MGs, thus improving the degradation rate of pollutants [52].
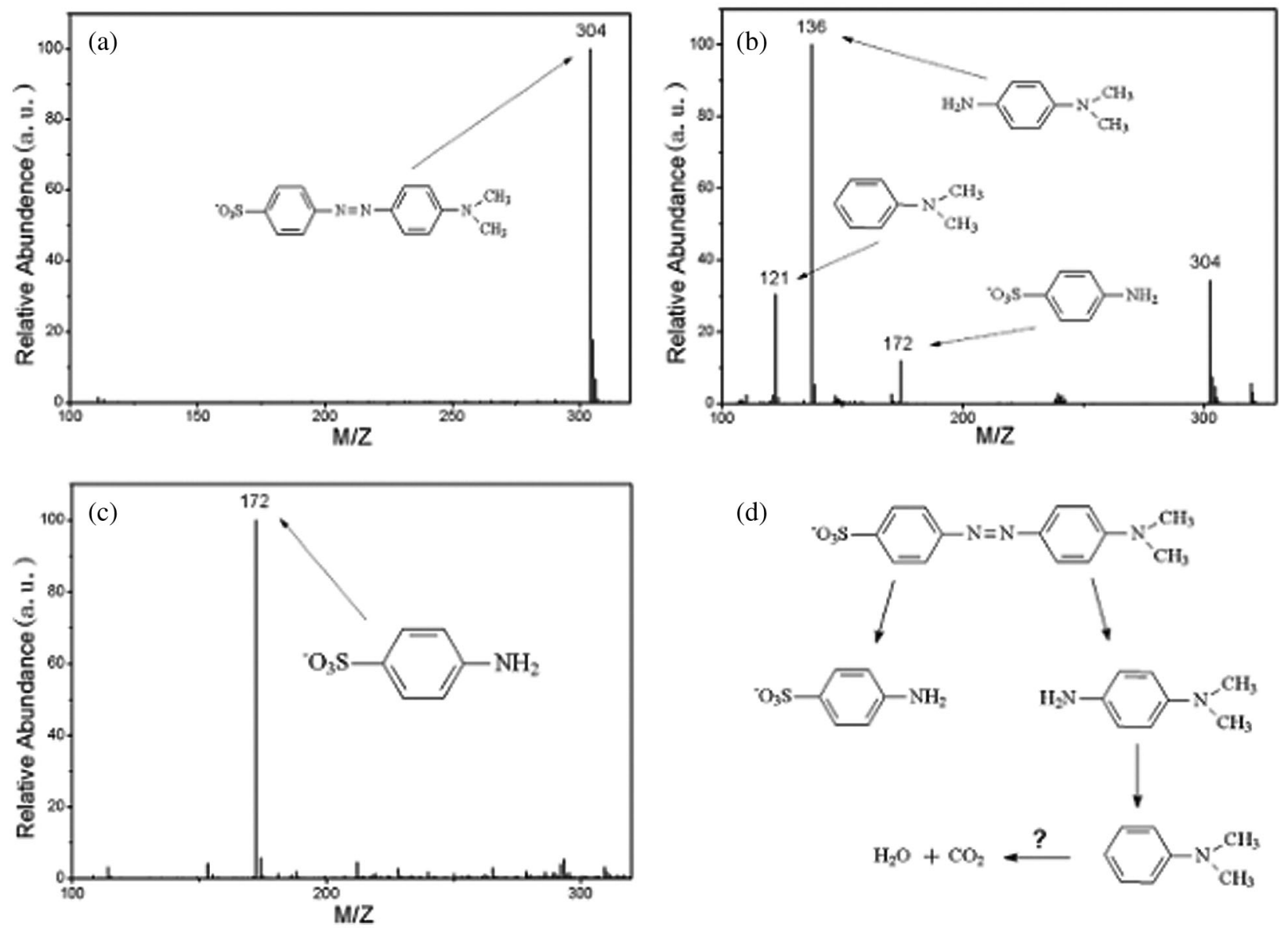

(d)
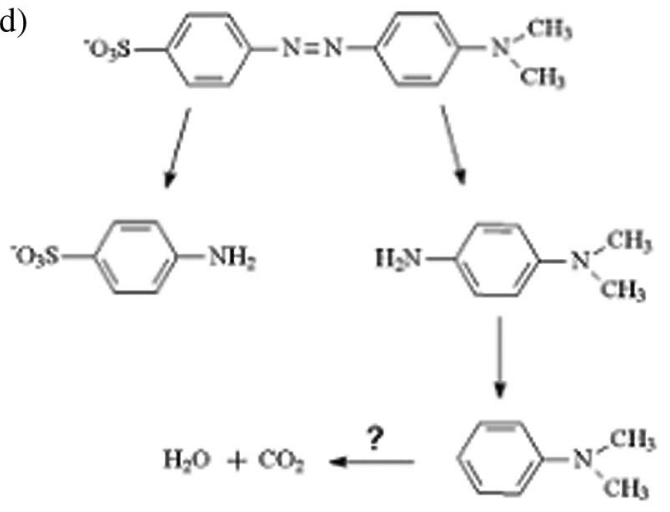

Figure 8: The ion spectra of full-scan products at different times. (a) start time; (b) reaction 10 min; (c) reaction $24 \mathrm{~h}$; (d) product formation sequence [39] 
Table 1: Decolorization rate of dye wastewater by MGs

\begin{tabular}{lllllll}
\hline $\begin{array}{l}\mathrm{MGs}\left({ }_{\mathrm{AP}} \text { is ribbon, }\right. \\
\text { is powder) }\end{array}$ & Preparation method & Dye & $\begin{array}{l}\text { Initial dye } \\
\text { concentration/mg/L }\end{array}$ & $\begin{array}{l}\text { Time/ } \\
\text { min }\end{array}$ & $\begin{array}{l}\text { Decolorization } \\
\text { rate/\% }\end{array}$ & Reference \\
\hline $\mathrm{Fe}_{78} \mathrm{Si}_{9} \mathrm{~B}_{13}{ }^{\mathrm{AR}}$ & Single roll strip casting & Orange II & 40 & 70 & 100 & {$[40]$} \\
$\mathrm{Fe}_{78} \mathrm{Si}_{8} \mathrm{~B}_{14}{ }^{\mathrm{AR}}$ & Single roll strip casting & Orange II & 100 & 30 & 100 & {$[41]$} \\
$\mathrm{Fe}_{80} \mathrm{P}_{13} \mathrm{C}_{7}{ }^{\mathrm{AR}}$ & Melt spinning & $\begin{array}{l}\text { Methylene } \\
\text { blue }\end{array}$ & 100 & 17 & 100 & {$[42]$} \\
$\mathrm{Fe}_{83.3} \mathrm{Si}_{4} \mathrm{~B}_{8} \mathrm{P}_{4} \mathrm{Cu}_{0.7}{ }^{\mathrm{AR}}$ & Melt spinning & Methyl orange & 20 & & & \\
$\mathrm{Fe}_{72} \mathrm{Si}_{2} \mathrm{~B}_{20} \mathrm{Nb}_{6}{ }^{\mathrm{AR}}$ & Melt spinning & Direct blue 15 & 50 & 40 & 100 & {$[43]$} \\
$\mathrm{Fe}_{78} \mathrm{Si}_{9} \mathrm{~B}_{13}{ }^{\mathrm{AR}}$ & Single roll strip casting & Acid Orange II & 200 & 60 & 100 & {$[44]$} \\
$\mathrm{Fe}_{78} \mathrm{Si}_{9} \mathrm{~B}_{13}{ }^{\mathrm{AP}}$ & Gas atomization & Direct blue 6 & 200 & 60 & 100 & {$[45]$} \\
\hline
\end{tabular}

Table 2: Removal rate of TOC in dye wastewater by several kinds of MGs

\begin{tabular}{llllll}
\hline MGs & Preparation method & Dye & $\begin{array}{l}\text { Time/ } \\
\text { min }\end{array}$ & $\begin{array}{l}\text { Removal } \\
\text { rate of TOC/\% }\end{array}$ & Reference \\
\hline $\mathrm{Fe}_{78} \mathrm{Si}_{9} \mathrm{~B}_{13}{ }^{\mathrm{AR}}$ & single roll strip casting & Congo red & 60 & 80 & {$[50]$} \\
$\mathrm{Fe}_{73.5} \mathrm{Si}_{13.5} \mathrm{~B}_{9} \mathrm{Cu}_{1} \mathrm{Nb}_{3}{ }^{\mathrm{AR}}$ & Melt spinning & Malachite green & 30 & 55 & {$[51]$} \\
$\mathrm{Fe}_{78} \mathrm{Si}_{9} \mathrm{~B}_{13}{ }^{\mathrm{AR}}$ & single roll strip casting & Methylene blue & 30 & 60 & {$[52]$} \\
$\mathrm{Fe}_{83} \mathrm{Si}_{2} \mathrm{~B}_{11} \mathrm{P}_{3} \mathrm{C}_{1}{ }^{\mathrm{AR}}$ & Melt spinning & Rhodamine B & 30 & 50 & {$[38]$} \\
& & Methylene blue & 5 & 60 & \\
& & Methyl orange & 30 & 63 & \\
& & Mixed dye & 15 & 55 & \\
\hline
\end{tabular}

\section{Treatment of Inorganic Salt Wastewater by MGs}

Based on the efficient degradation of organic dyes by MGs, in recent years, researchers have applied it to the treatment of wastewater polluted by heavy metals, metal-like and inorganic acid ions and achieved good results. Yan et al. [54] used $\mathrm{Fe}_{78} \mathrm{Si}_{9} \mathrm{~B}_{13}{ }^{\mathrm{AR}}$ to treat wastewater polluted by $\mathrm{Cu}^{2+}$ ions. The initial concentration of $\mathrm{Cu}^{2+}$ ions was $500 \mathrm{mg} / \mathrm{L}$, and the dosage of ribbon was $2 \mathrm{~g} / \mathrm{L}$. After $60 \mathrm{~min}$ of reaction, the concentration of $\mathrm{Cu}^{2+}$ ions decrease to $1 \mathrm{mg} / \mathrm{L}$, and the color of the solution change from light green to colorless. The $\mathrm{Fe}$ in the ribbon reacts with the $\mathrm{Cu}^{2+}$ ions in the solution (as shown in Fig. 9), and the $\mathrm{Cu}^{2+}$ ions is precipitate from the solution in the form of copper. The reaction rate constant obtained by fitting the quasi-first-order kinetic equation is $0.0667 \mathrm{~min}^{-1}$. However, under the same reaction conditions, the rate constant of the reaction of ZVI with $\mathrm{Cu}^{2+}$ ions is $0.0344 \mathrm{~min}^{-1}$. For the reason why $\mathrm{Fe}_{78} \mathrm{Si}_{9} \mathrm{~B}_{13}{ }^{\mathrm{AR}}$ can efficiently reduce $\mathrm{Cu}^{2+}$ ions, Zhang et al. [55] observed by SEM that there is a great difference in the structure and morphology between the amorphous bands and the surface products of ZVI. As shown in Fig. 10, the product layer on the surface of the amorphous ribbons has a pore structure perpendicular to the reaction interface, which is beneficial to the diffusion of $\mathrm{Cu}^{2+}$ ions to the reaction interface. However, the product layer of ZVI is irregularly arranged in the dendritic shape, which closely covers the surface of ZVI and hinders the transmission of $\mathrm{Cu}^{2+}$ ions, which is one of the reasons for the low activity of ZVI reaction. Liang et al. [56] remediated groundwater contaminated by $\mathrm{As}^{5+}$ ions and $\mathrm{NO}_{3}{ }^{-}$ions by reductive precipitation. When $\mathrm{Fe}_{78} \mathrm{Si}_{9} \mathrm{~B}_{13}{ }^{\mathrm{AR}}$ and $\mathrm{Na}_{2} \mathrm{~S}$ were added to the polluted groundwater at the same time, $\mathrm{Fe}_{78} \mathrm{Si}_{9} \mathrm{~B}_{13}{ }^{\mathrm{AR}}$ reduced $\mathrm{As}^{5+}$ ions to $\mathrm{As}^{3+}$ ions and then combined with $\mathrm{S}^{2-}$ ions to form $\mathrm{As}_{2} \mathrm{~S}_{3}$ precipitation. The maximum amount of $\mathrm{As}^{5+}$ ions removal is up to $95 \%$ at $25^{\circ} \mathrm{C}^{-} \mathrm{NO}_{3}{ }^{-}$can be removed from aqueous solution in three ways: (1) under acidic conditions, $\mathrm{NO}_{3}{ }^{-}$is reduced by iron to $\mathrm{NH}_{4}{ }^{+}$(Eq. (1)). (2) $\mathrm{NO}_{3}{ }^{-}$ 
is reduced to $\mathrm{N}_{2}$ and $\mathrm{OH}^{-}$by Eq. (2), (3) The generated $\mathrm{Fe}^{2+}$ ions is oxidized to $\mathrm{Fe}^{3+}$ ions and then combined with $\mathrm{OH}^{-}$to form $\mathrm{Fe}(\mathrm{OH})_{3}$ with water purification function (Eq. (3)). The unreduced $\mathrm{NO}_{3}{ }^{-}$is removed from the water by $\mathrm{Fe}(\mathrm{OH})_{3}$ adsorption. The ribbons still maintained high reaction activity after being reused for 20 times. At present, the research on the treatment of inorganic salt wastewater by MGs is less and the type of ions is single, so it needs to be further explored in the future.

$$
\begin{aligned}
& 4 \mathrm{Fe}+\mathrm{NO}^{3-}+10 \mathrm{H}^{+} \rightarrow 4 \mathrm{Fe}^{2+}+\mathrm{NH}^{4+}+3 \mathrm{H}_{2} \mathrm{O} \\
& 5 \mathrm{Fe}+2 \mathrm{NO}^{3-}+6 \mathrm{H}_{2} \mathrm{O} \rightarrow 5 \mathrm{Fe}^{2+}+\mathrm{N}_{2}+12 \mathrm{OH}^{-} \\
& 4 \mathrm{Fe}^{2+}+8 \mathrm{OH}^{-}+\mathrm{O}_{2}+2 \mathrm{H}_{2} \mathrm{O} \rightarrow 4 \mathrm{Fe}(\mathrm{OH})_{3}
\end{aligned}
$$

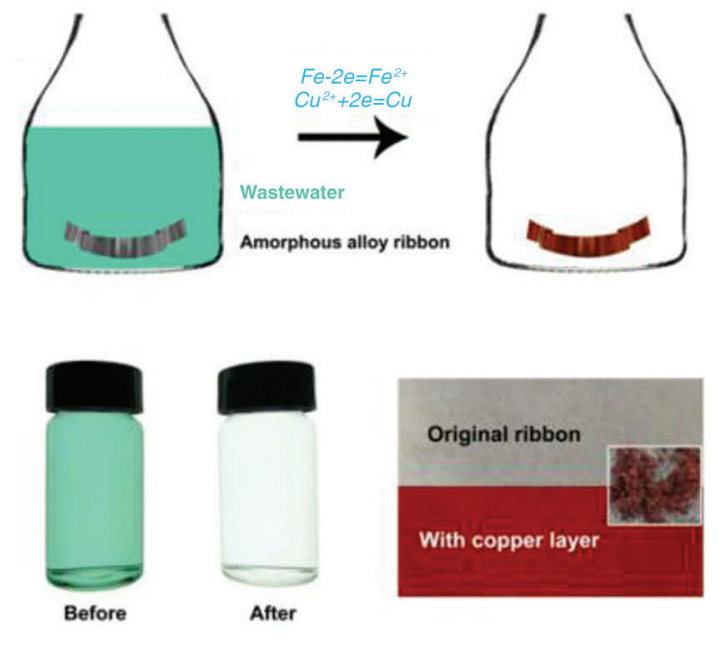

(a)

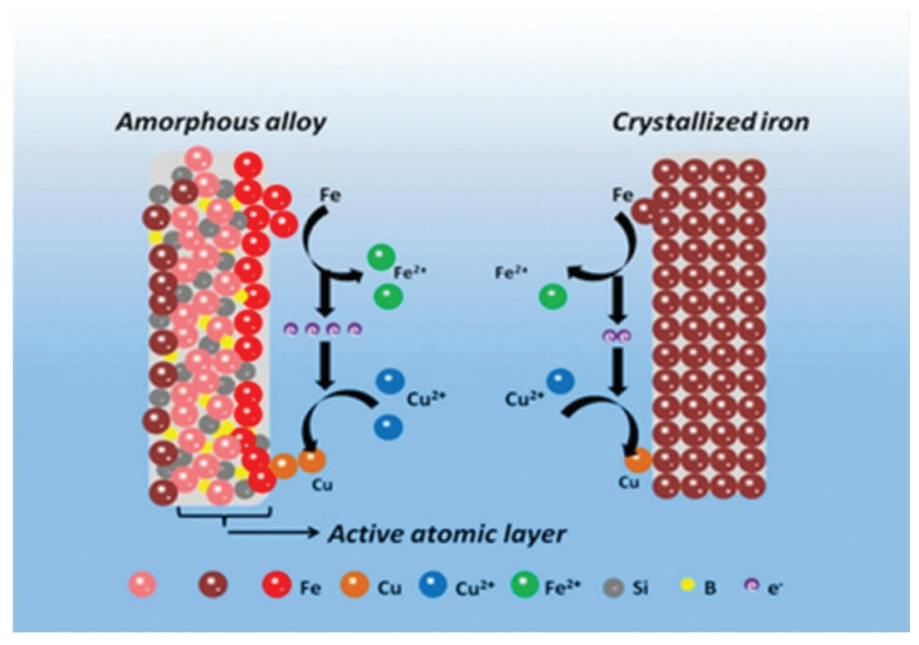

(b)

Figure 9: $\mathrm{Fe}_{78} \mathrm{Si}_{9} \mathrm{~B}_{13}{ }^{\mathrm{AR}}$ treatment of $\mathrm{Cu}^{2+}$ contaminated wastewater: (a) color change; (b) reaction mechanism [54]

\section{Degradation Mechanism}

The degradation mechanism of pollutants by Fe-MGs can be divided into two kinds: one is to make use of the electronegativity of ZVI to reduce the pollutants directly to achieve the purpose of degradation. The other is to produce strong oxidizing hydroxyl radical $\mathrm{OH}$ by fenton method to oxidize and remove the pollutants. Fig. 11 shows the reaction process of the two degradation mechanisms.

\subsection{Direct Reduction}

The redox reaction is easy to occur, which requires the reductant to have a negative electrode potential and the oxidant to have a positive electrode potential. The standard electrode potential of Fe is $-0.44 \mathrm{~V}$, which has good reducibility in the removal of organic matter and oxidizing pollutants. As shown in Eqs. (4)-(11), When Fe comes into contact with pollutants, it is easy to lose electrons and convert them into $\mathrm{Fe}^{2+}$ or $\mathrm{Fe}^{3+}$ ions. The electrons generated are captured by organic compounds or heavy metal salts to reduce and degrade the pollutants. In addition, $\mathrm{Fe}$ reacts with $\mathrm{H}_{2} \mathrm{O}$ or $\mathrm{H}^{+}$ions to form an active hydrogen atom $[\mathrm{H}]$, which has a strong reducibility, resulting in the breaking of the chemical bond $(-\mathrm{N}=\mathrm{N}-)$ in the molecules of organic pollutants [57]. Therefore, as a traditional environmental functional material, ZVI have been widely used in the treatment of groundwater or industrial wastewater. 


$$
\begin{aligned}
& \mathrm{Fe}^{0} \rightarrow \mathrm{Fe}^{2+}+2 \mathrm{e}^{-} \\
& \mathrm{Fe}^{2+} \rightarrow \mathrm{Fe}^{3+}+\mathrm{e}^{-} \\
& 2 \mathrm{H}_{2} \mathrm{O}(\mathrm{l})+2 \mathrm{e}^{-} \rightarrow \mathrm{H}_{2}(\mathrm{~g})+2 \mathrm{OH}^{-}(\mathrm{aq}) \\
& \mathrm{H}_{2} \mathrm{O}(\mathrm{l}) \rightarrow \mathrm{H}^{+}(\mathrm{aq})+\mathrm{OH}^{-}(\mathrm{aq}) \\
& \mathrm{H}^{+}(\mathrm{aq})+\mathrm{e}^{-} \rightarrow[\mathrm{H}] \\
& {[\mathrm{H}]+[\mathrm{H}] \rightarrow \mathrm{H}_{2}(\mathrm{~g})} \\
& \mathrm{R}-\mathrm{N}=\mathrm{N}-\mathrm{R}^{\prime}+4 \mathrm{H}+(\mathrm{aq})+4 \mathrm{e}^{-} \rightarrow \mathrm{R}-\mathrm{NH}_{2}+\mathrm{R}^{\prime}-\mathrm{NH}_{2} \\
& \mathrm{R}-\mathrm{N}=\mathrm{N}-\mathrm{R}^{\prime}+4[\mathrm{H}] \rightarrow \mathrm{R}-\mathrm{NH}_{2}+\mathrm{R}^{\prime}-\mathrm{NH}_{2}
\end{aligned}
$$
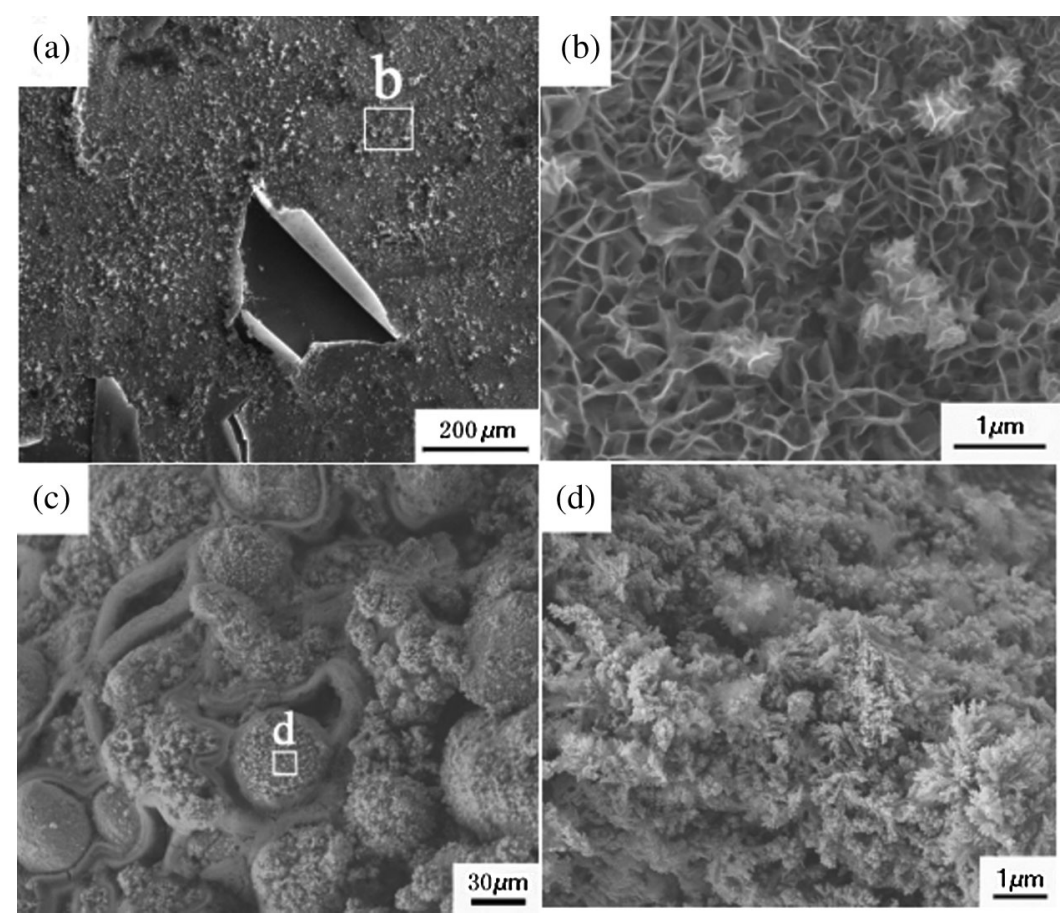

Figure 10: The product morphology of $\mathrm{Fe}_{79} \mathrm{Si}_{13} \mathrm{~B}_{8}{ }^{\mathrm{AR}}$ and $\mathrm{ZVI}$ : (a) $\mathrm{Fe}_{79} \mathrm{Si}_{13} \mathrm{~B}_{8}{ }^{\mathrm{AR}}$; (b) is the high resolution map of b region in (a); (c) ZVI; (d) is the high resolution map of d region in (c) [55]

Fe-MGs is a special kind of ZVI, in order to compare the difference between Fe-MGs and ZVI in the treatment of pollutants, some researchers have carried out the kinetic analysis of the reaction process. Tang et al. [58] used amorphous ribbons $\mathrm{Fe}_{86} \mathrm{~B}_{14}{ }^{\mathrm{AR}}$, crystalline ribbons $\mathrm{Fe}_{86} \mathrm{~B}_{14}{ }^{\mathrm{CR}}$, and $\mathrm{ZVI}$ to degrade Direct Blue 6 under the same external conditions. The apparent reaction rate constant $\mathrm{k}_{\text {obs }}$ was obtained by fitting the quasi-first-order kinetic equation (Eq. (12)). It is found that the $\mathrm{k}_{\text {obs }}$ of $\mathrm{Fe}_{86} \mathrm{~B}_{14}{ }^{\mathrm{AR}}$ in the degradation reaction is 1.8 and 89 times higher than that of $\mathrm{Fe}_{86} \mathrm{~B}_{14}{ }^{\mathrm{CR}}$ and ZVI, respectively, indicating that the catalytic rate of amorphous materials is higher than that of crystalline materials. In addition, the formation of oxide layer can be controlled by fine-tuning the content of B, which can further improve the catalytic efficiency of Fe-B amorphous ribbons. On this basis, Tang et al. [59] further explored the degradation process of orange II by ternary amorphous ribbons $\mathrm{Fe}_{79} \mathrm{Si}_{13} \mathrm{~B}_{8}{ }^{\mathrm{AR}}$ and ZVI. Using Arrhenius 
formula (Eq. (13)), the apparent activation energy $\Delta \mathrm{E}$ of $\mathrm{Fe}_{79} \mathrm{Si}_{13} \mathrm{~B}_{8}{ }^{\mathrm{AR}}$ is $17.98 \mathrm{~kJ} / \mathrm{mol}$, and that of ZVI is $31.98 \mathrm{~kJ} / \mathrm{mol}$. Therefore, $\mathrm{Fe}_{79} \mathrm{Si}_{13} \mathrm{~B}_{8}{ }^{\mathrm{AR}}$ is more likely to be excited to change from a conventional state to an active state capable of chemical reaction. Fig. 12 compares the $\Delta \mathrm{E}$ of Fe-MGs and ZVI in the degradation of typical azo dyes acid orange (a) and direct blue 6 (b). For the same dye, the $\Delta \mathrm{E}$ of all FeMGs is lower than that of ZVI, indicating that Fe-MGs in metastable state have higher reaction activity than crystalline ZVI, which are more suitable to be used as environmental functional materials in the field of water treatment. In order to show that Fe-MGs generally have higher $\mathrm{k}_{\mathrm{obs}}$ and lower $\Delta \mathrm{E}$ in catalytic reaction, the kinetic parameters of catalytic degradation of various dyes by different Fe-MGs are summarized in Table 3.

$\ln \left(C_{\mathrm{t}} / C_{0}\right)=-k_{\mathrm{obs}} \cdot t$

$\ln k_{\mathrm{T}}=\Delta E / \mathrm{R} T+\ln \mathrm{A}$

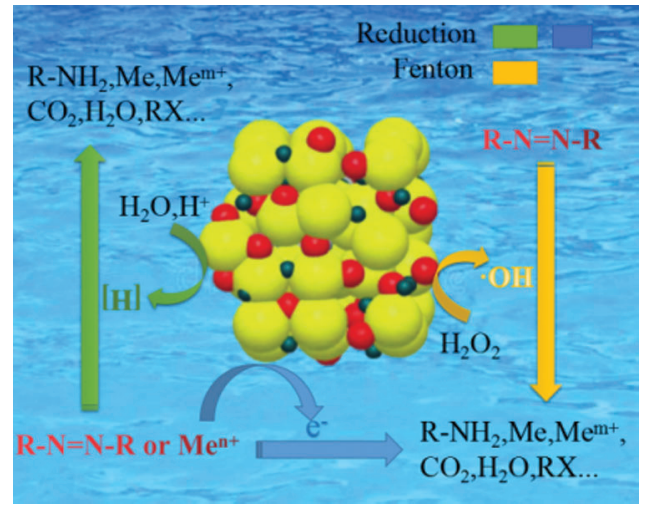

Figure 11: Reaction process of reduction and oxidation mechanism
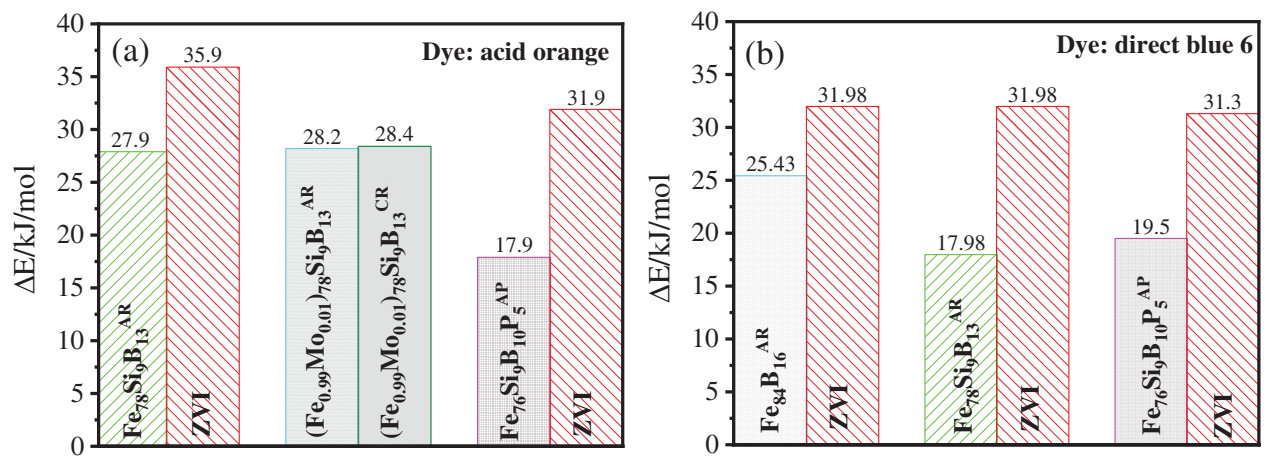

Figure 12: $\Delta \mathrm{E}$ in the degradation of acid orange (a) and direct blue 6 (b) by Fe-MGs and ZVI [38,58-60]

The above results explain why MGs have higher catalytic activity than crystalline materials from the point of view of kinetics, but it is still at the apparent level. Through the redox potential of MGs in dye wastewater, some researchers explained the deep reason why the $\mathrm{k}_{\mathrm{obs}}$ of $\mathrm{MGs}$ is higher and $\Delta \mathrm{E}$ is lower. Weng et al. [64] measured that the redox potentials of $\mathrm{Fe}_{85} \mathrm{~B}_{15}{ }^{\mathrm{AP}}$ and $\mathrm{Fe}_{76} \mathrm{Si}_{9} \mathrm{~B}_{10} \mathrm{P}_{5}{ }^{\mathrm{AP}}$ in methyl orange solution are $-0.47 \mathrm{~V}$ and $-0.45 \mathrm{~V}$, respectively, which are lower than the redox potential of ZVI $-0.437 \mathrm{~V}$. Therefore, $\mathrm{Fe}_{85} \mathrm{~B}_{15}{ }^{\mathrm{AP}}$ and $\mathrm{Fe}_{76} \mathrm{Si}_{9} \mathrm{~B}_{10} \mathrm{P}_{5}{ }^{\mathrm{AP}}$ have stronger reductivity. Zhang et al. [55] measured 
the potentiodynamic polarization curves of pure iron strips and $\mathrm{Fe}-\mathrm{Si}$-B amorphous strips in $\mathrm{CuSO}_{4}$ solution. The electrode potential of Fe-Si-B amorphous ribbons is lower than that of pure iron ribbons due to the presence of non-metallic elements $\mathrm{Si}$ and $\mathrm{B}$ in the amorphous ribbons. This result also explains the inherent reason why the $\mathrm{k}_{\mathrm{obs}}$ of the reaction of $\mathrm{Fe}-\mathrm{Si}$-B amorphous ribbons with $\mathrm{Cu}^{2+}$ ions is higher than that of ZVI. In order to determine whether the atomic disorder stacking structure in MGs is one of the reasons for the decrease of redox potential, Tang [60] measured the open circuit potential of $\mathrm{Fe}_{78} \mathrm{Si}_{9} \mathrm{~B}_{13}{ }^{\mathrm{AR}}, \mathrm{Fe}_{78} \mathrm{Si}_{9} \mathrm{~B}_{13}{ }^{\mathrm{CR}}$, and $\mathrm{ZVI}$ in methyl orange wastewater under the same external conditions as $-0.735 \mathrm{~V},-0.471 \mathrm{~V}$, and $-0.439 \mathrm{~V}$, respectively. Comparing the open circuit potential of $\mathrm{Fe}_{78} \mathrm{Si}_{9} \mathrm{~B}_{13}{ }^{\mathrm{AR}}$ and $\mathrm{Fe}_{78} \mathrm{Si}_{9} \mathrm{~B}_{13}{ }^{\mathrm{CR}}$, it is found that the open circuit voltage of the alloy with the same nominal composition is different due to the different arrangement of internal atoms. Therefore, it can be determined that the disorder stacking structure of atoms in MGs is one of the reasons for the decrease of redox potential.

Table 3: The $\mathrm{k}_{\mathrm{obs}}$ and $\Delta \mathrm{E}$ in the degradation of dyes by Fe-MGs

\begin{tabular}{|c|c|c|c|c|c|c|c|}
\hline MGs & Dye & $\begin{array}{l}\text { Temperature/ } \\
\mathrm{K}\end{array}$ & $\begin{array}{l}\mathrm{k}_{\mathrm{obs}} / \\
\mathrm{min}^{-1}\end{array}$ & $\begin{array}{l}\Delta \mathrm{E} / \mathrm{kJ} / \\
\mathrm{mol}\end{array}$ & $\begin{array}{l}\text { Control } \\
\text { steps }\end{array}$ & $\begin{array}{l}\text { Degradation } \\
\text { rate } / \%\end{array}$ & Reference \\
\hline \multirow[t]{4}{*}{$\mathrm{Fe}_{78} \mathrm{Si}_{9} \mathrm{~B}_{13}{ }^{\mathrm{AR}}$} & \multirow[t]{4}{*}{ Acid orange II } & 298 & 0.174 & \multirow[t]{4}{*}{35.9} & \multirow{4}{*}{$\begin{array}{l}\text { Surface } \\
\text { control }\end{array}$} & \multirow[t]{4}{*}{96.7} & \multirow[t]{4}{*}{ [61] } \\
\hline & & 303 & 0.205 & & & & \\
\hline & & 313 & 0.299 & & & & \\
\hline & & 323 & 0.412 & & & & \\
\hline \multirow[t]{4}{*}{$\left(\mathrm{Fe}_{0.99} \mathrm{Mo}_{0.01}\right)_{78} \mathrm{Si}_{9} \mathrm{~B}_{13}{ }^{\mathrm{AR}}$} & \multirow[t]{4}{*}{ Acid orange II } & 298 & 0.168 & \multirow[t]{4}{*}{28.4} & \multirow{4}{*}{$\begin{array}{l}\text { Diffusion } \\
\text { control }\end{array}$} & \multirow[t]{4}{*}{97.8} & \multirow[t]{4}{*}{ [62] } \\
\hline & & 303 & 0.185 & & & & \\
\hline & & 313 & 0.282 & & & & \\
\hline & & 323 & 0.407 & & & & \\
\hline \multirow[t]{4}{*}{$\mathrm{Fe}_{63} \mathrm{Cr}_{5} \mathrm{Nb}_{4} \mathrm{Y}_{6} \mathrm{~B}_{22}{ }^{\mathrm{AR}}$} & Methylene & 283 & 0 & \multirow[t]{4}{*}{21.8} & \multirow{4}{*}{$\begin{array}{l}\text { Diffusion } \\
\text { control }\end{array}$} & \multirow[t]{4}{*}{95.0} & \multirow[t]{4}{*}{ [63] } \\
\hline & \multirow[t]{3}{*}{ blue } & 303 & 0.087 & & & & \\
\hline & & 323 & 0.182 & & & & \\
\hline & & 343 & 0.239 & & & & \\
\hline \multirow[t]{8}{*}{$\mathrm{Fe}_{76} \mathrm{Si}_{9} \mathrm{~B}_{10} \mathrm{P}_{5}{ }^{\mathrm{AP}}$} & \multirow[t]{4}{*}{ Methyl orange } & 298 & 0.151 & \multirow[t]{4}{*}{19.5} & \multirow{4}{*}{$\begin{array}{l}\text { Diffusion } \\
\text { control }\end{array}$} & \multirow[t]{4}{*}{96.0} & \multirow[t]{8}{*}{ [64] } \\
\hline & & 308 & 0.196 & & & & \\
\hline & & 318 & 0.251 & & & & \\
\hline & & 328 & 0.298 & & & & \\
\hline & \multirow[t]{4}{*}{ Direct blue 6} & 298 & 0.241 & \multirow[t]{4}{*}{26.8} & \multirow{4}{*}{$\begin{array}{l}\text { Diffusion } \\
\text { control }\end{array}$} & \multirow[t]{4}{*}{97.6} & \\
\hline & & 308 & 0.297 & & & & \\
\hline & & 318 & 0.346 & & & & \\
\hline & & 328 & 0.388 & & & & \\
\hline
\end{tabular}

Note: $\Delta \mathrm{E}$ in the range of $8-21 \mathrm{~kJ} / \mathrm{mol}$ is controlled by diffusion in solution, and $\Delta \mathrm{E}>29 \mathrm{~kJ} / \mathrm{mol}$ is controlled by surface control [65]. 
When Fe-MGs degrades pollutants through direct reduction mechanism, the Fe in Fe-MGs loses the outermost electrons as a reducing agent. From the analysis of the above experimental results, it is found that Fe-MGs have higher reducibility than the same component crystalline alloy and ZVI, that is, the outermost electrons of Fe-MGs are easier to break away from the binding force of the nucleus and transfer to the contaminants. In order to compare the electron loss ability of amorphous and crystalline materials, Zhang et al. [66] analyzed the valence band densities of states of $\mathrm{Fe}_{78} \mathrm{Si}_{8} \mathrm{~B}_{14}{ }^{\mathrm{AR}}$ and $\mathrm{ZVI}$ by $\mathrm{X}$-ray photoelectron spectroscopy as shown in Fig. 13. There is an obvious difference in the energy band structure between the two materials. The valence band top of $\mathrm{Fe}_{78} \mathrm{Si}_{8} \mathrm{~B}_{14}{ }^{\mathrm{AR}}$ is $0.16 \mathrm{eV}$ lower than that of ZVI, and the empty band is widened accordingly, which makes it easier for electrons in $4 \mathrm{~s}$ orbitals to overcome the energy barrier and be activated into the empty band. Therefore, in the process of reductive degradation of dyes, $\mathrm{Fe}_{78} \mathrm{Si}_{8} \mathrm{~B}_{14}{ }^{\mathrm{AR}}$ can provide more excited electrons to participate in the catalytic reaction. The simple disordered stacking of atoms can make the electrons get rid of the constraints of the lattice, which shows the superiority of MGs structure.

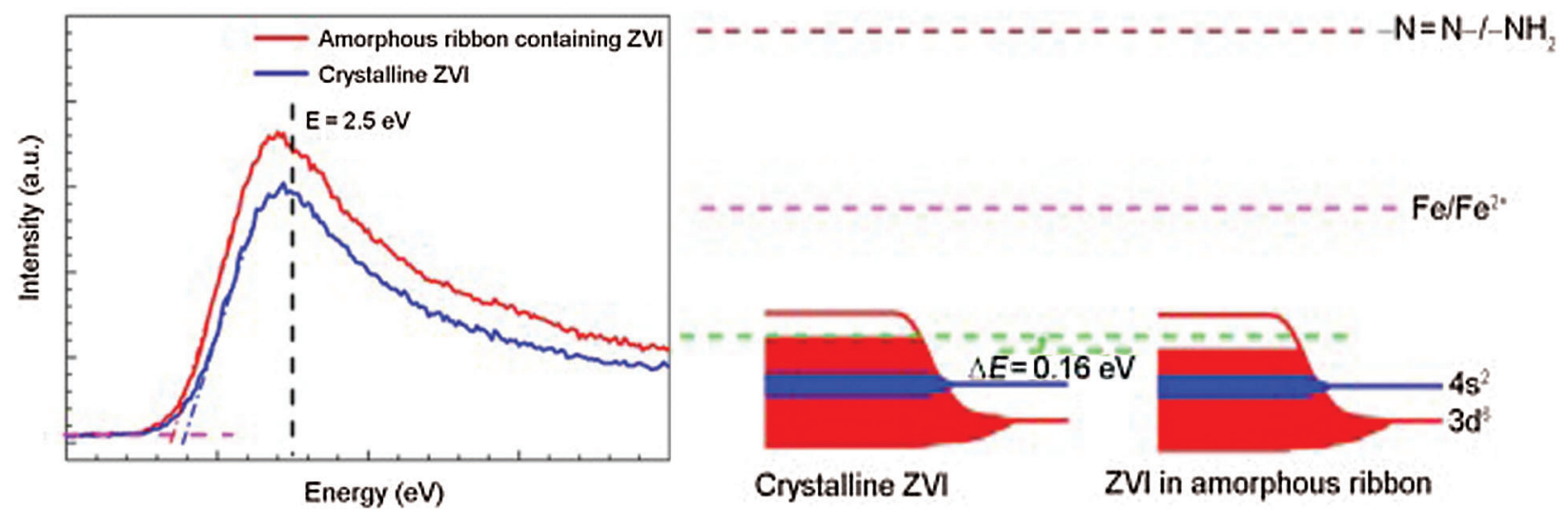

(a)

(b)

Figure 13: (a) Total Valence Band density of States of ZVI and $\mathrm{Fe}_{78} \mathrm{Si}_{8} \mathrm{~B}_{14}{ }^{\mathrm{AR}}$; (b) Schematic diagrams of different electronic structures of ZVI and $\mathrm{Fe}_{78} \mathrm{Si}_{8} \mathrm{~B}_{14}{ }^{\mathrm{AR}}$ [66]

\subsection{Advanced Oxidation}

Advanced oxidation is a new purification technology for oxidative degradation of organic pollutants, which mainly includes ozonation, photocatalysis, and fenton method [67,68]. Iron-based materials are mainly oxidized and degraded by fenton method. The principle is that $\mathrm{Fe}^{2+}$ ions reacts with fenton agent $\mathrm{H}_{2} \mathrm{O}_{2}$ to form strong oxidizing $\mathrm{OH}$ (formula 14), and its redox potential can reach $2.7 \mathrm{~V}$. The generated $\cdot \mathrm{OH}$ can quickly oxidize and decompose organic pollutants into $\mathrm{CO}_{2}, \mathrm{H}_{2} \mathrm{O}$, and inorganic small molecular substances. During this process, when $\mathrm{Fe}^{2+}$ ions is converted to $\mathrm{Fe}^{3+}$ ions, it cannot continue to generate $\mathrm{OH}$. Moreover, $\mathrm{Fe}^{3+}$ ions can also consume $\mathrm{H}_{2} \mathrm{O}_{2}$ to produce $\mathrm{HO}_{2}$. with negative redox potential (Eq. (15)), which seriously inhibits the oxidative decomposition of organic pollutants. At this time, if there is ZVI in the solution, the generated $\mathrm{Fe}^{3+}$ ions can be reduced to $\mathrm{Fe}^{2+}$ ions again (Eq. (16)) to participate in the formation of $\mathrm{OH}$. The traditional ZVI is easy to be passivated due to the adhesion of the reaction products on its surface, which reduces the long-term reaction activity of ZVI. Using Fe-MGs instead of ZVI can effectively alleviate the passivation phenomenon on the surface of the material and reduce the amount of catalyst. 
$\mathrm{Fe}^{2+}+\mathrm{H}_{2} \mathrm{O}_{2} \rightarrow \mathrm{Fe}^{3+}+\mathrm{OH}^{-}+\cdot \mathrm{OH}$

$\mathrm{Fe}^{3+}+\mathrm{H}_{2} \mathrm{O}_{2} \rightarrow \mathrm{Fe}^{2+}+\mathrm{HO}_{2} \cdot+\mathrm{H}^{+}$

$\mathrm{Fe}+2 \mathrm{Fe}^{3+} \rightarrow 3 \mathrm{Fe}^{2+}$

As the effect of fenton reaction on the degradation of pollutants is greatly affected by the external environment, some researchers explore the best process parameters under different experimental conditions. Wang et al. [69] studied the effects of temperature, $\mathrm{pH}$, and $\mathrm{H}_{2} \mathrm{O}_{2}$ concentration on the degradation of rhodamine $\mathrm{B}$. The results show that the complete degradation of rhodamine $\mathrm{B}$ can be achieved in about $10 \mathrm{~min}$ by adding $0.5 \mathrm{~g} \mathrm{Fe}_{78} \mathrm{Si}_{9} \mathrm{~B}_{13}{ }^{\mathrm{AR}}$ catalyst and $1.6 \mathrm{~mol} / \mathrm{L} \mathrm{H}_{2} \mathrm{O}_{2}$ to the solution of rhodamine $\mathrm{B}$ at the temperature of $295 \mathrm{~K}$ and $\mathrm{pH}=3$ and the concentration of $20 \mathrm{mg} / \mathrm{L}$. The degradation process accords with the description of pseudo-first-order kinetic model. The strips still have good structural stability after being reused for three times, and there are no obvious performance loss. The most direct factor affecting the efficiency of oxidative degradation is the amount of $\cdot \mathrm{OH}$. Properly increasing the amount of catalyst and $\mathrm{H}_{2} \mathrm{O}_{2}$ is helpful to the rapid formation of $\cdot \mathrm{OH}$. Jia et al. [49] used $\mathrm{Fe}_{78} \mathrm{Si}_{9} \mathrm{~B}_{13}{ }^{\mathrm{AR}}$ and $\mathrm{Fe}_{73.5} \mathrm{Si}_{13.5} \mathrm{~B}_{9} \mathrm{Cu}_{1} \mathrm{Nb}_{3}{ }^{\mathrm{AR}}$ as catalysts to degrade brilliant red by fenton. As shown in Fig. 14, with the increase of amorphous ribbons and $\mathrm{H}_{2} \mathrm{O}_{2}$ content, the rate of catalytic degradation increases and the decolorization rate increases. According to Eq. (17), it can be understood that more effective $\mathrm{Fe}^{2+}$ ions can be extracted from the ribbons with higher fenton dosage. However, when the concentration of $\mathrm{Fe}^{2+}$ ions in the solution is too high, it will react with $\cdot \mathrm{OH}$ (Eq. (18)), and the consumption of the resulting $\cdot \mathrm{OH}$ leads to the decrease of degradation efficiency [70].

$\mathrm{Fe}+\mathrm{H}_{2} \mathrm{O}_{2}=\mathrm{Fe}^{2+}+2 \mathrm{OH}^{-}$

$\mathrm{Fe}^{2+}+\cdot \mathrm{OH}=\mathrm{Fe}^{3+}+\mathrm{OH}^{-}$
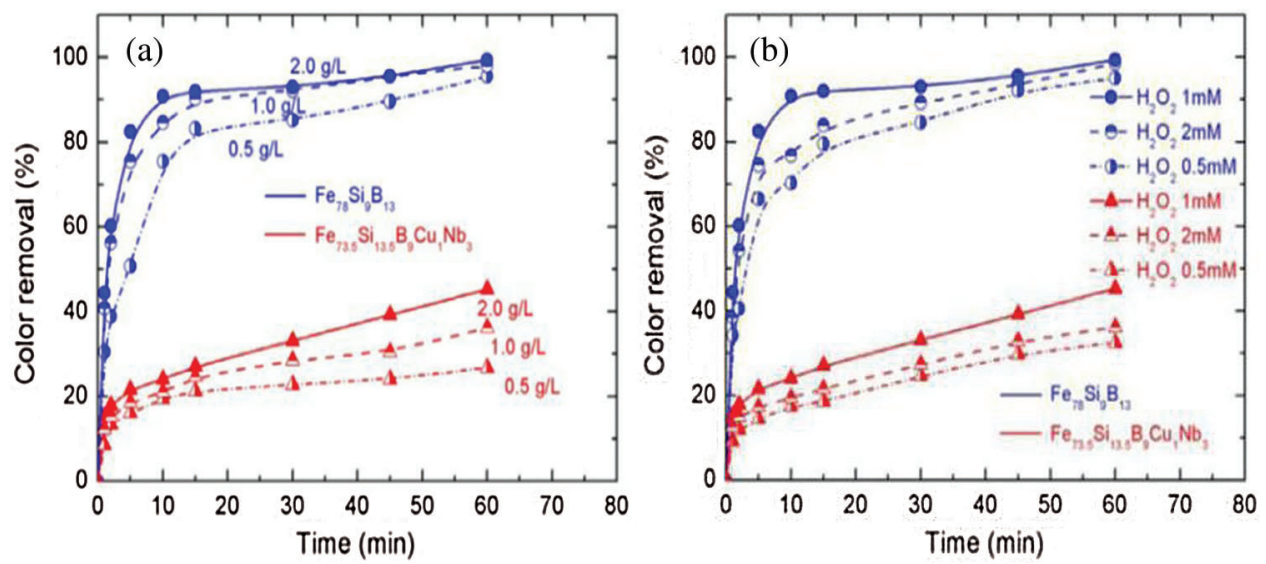

Figure 14: Effect of fenton concentration on decolorization rate of brilliant red $3 \mathrm{~B}-\mathrm{A}$ : (a) $\mathrm{Fe}_{78} \mathrm{Si}_{9} \mathrm{~B}_{13}{ }^{\mathrm{AR}}$ and $\mathrm{Fe}_{73.5} \mathrm{Si}_{13.5} \mathrm{~B}_{9} \mathrm{Cu}_{1} \mathrm{Nb}_{3}{ }^{\mathrm{AR}}$; (b) $\mathrm{H}_{2} \mathrm{O}_{2}$ [49]

The fenton system can be carried out spontaneously without external energy. If the external energy can be input in the reaction process, the catalytic performance of the system can be effectively improved. For example, increasing the temperature of the system can significantly increase the reaction rate, because at high temperature, the reactant can easily cross the energy barrier to an active state capable of chemical reaction. At the same time, high temperature is beneficial to the diffusion of matter and accelerate the reaction [69]. Light radiation is also an effective way of energy input. When the fenton system is irradiated with high intensity light, the rate of photochemical reaction of $\mathrm{Fe}^{3+}$ ions to $\mathrm{Fe}^{2+}$ ions is 
accelerated through Eq. (19). This is because the unstable electrons of $4 \mathrm{~s}^{2}$ orbitals in amorphous Fe atoms are easily activated, resulting in rapid electron transfer [71]. In order to improve the light energy efficiency of MGs, Yang et al. [72] prepared composites $\mathrm{MGs} / \mathrm{TiO}_{2}$ by doping $\mathrm{TiO}_{2}$ into $\mathrm{Fe}_{78} \mathrm{Si}_{9} \mathrm{~B}_{13}{ }^{\mathrm{AP}}$. Under visible light irradiation, the decolorization rate of methylene blue degraded by $\mathrm{TiO}_{2}$ is 3 times higher than that of crystalline alloy $(\mathrm{CA}) / \mathrm{TiO}_{2}$ (Fig. 15a). The synergistic strengthening mechanism of $\mathrm{MGs} / \mathrm{TiO}_{2}$ is shown in Fig. 15b. The action mechanism of MGs is similar to that of ZVI, but it has enhanced performance. The catalyst is excited by photons, and the electrons transition from the valence band (VB) of $\mathrm{TiO}_{2}$ to the conduction band (CB), resulting in electron-hole pairs. The electrons produced by $\mathrm{TiO}_{2}$ prevent the formation of oxide layer on the surface of metallic glass by reducing $\mathrm{Fe}^{3+}$ ions to $\mathrm{Fe}^{2+}$ ions.

$\mathrm{Fe}(\mathrm{OH})^{2+}+\mathrm{hv}=\cdot \mathrm{OH}+\mathrm{Fe}^{2+}$

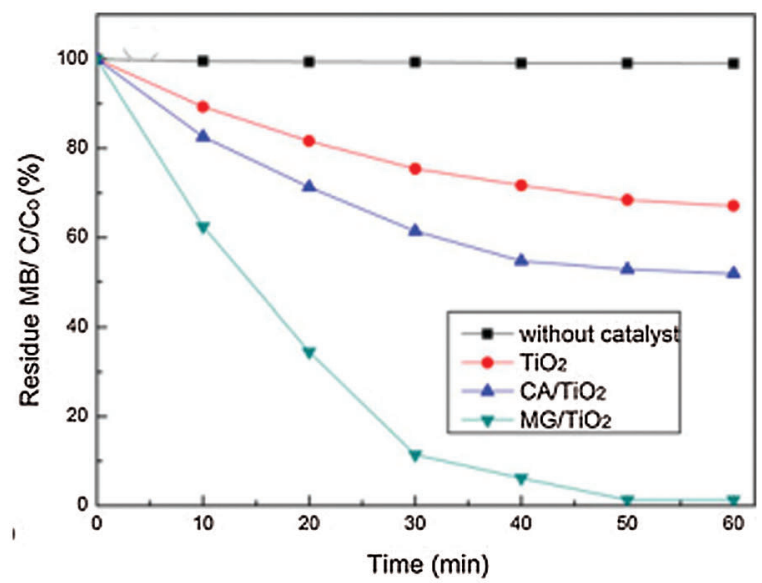

(a)

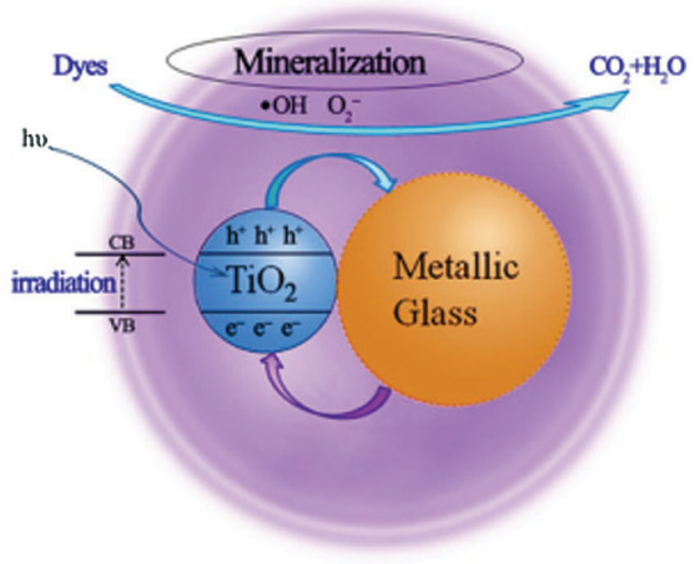

(b)

Figure 15: Decolorization rate (a) and reaction mechanism (b) of methylene blue degraded by $\mathrm{MGs} / \mathrm{TiO}_{2}[72]$

\section{Reuse of MGs}

Reuse is one of the important indicators of environmental functional materials, which determines whether the materials can be applied in large-scale engineering. Fe-MGs have a good structural stability in the catalytic reaction, and the surface oxide layer is loose and easy to fall off, so it is not easy to passivate, which is conducive to the effective contact between the catalyst and pollutants, so that the catalytic reaction can occur continuously. In order to test the reusable times of Fe-MGs, the ribbons after reaction were filtered from the water after each degradation experiment. Under the premise of not destroying the surface products of the ribbons, the ribbons were washed with deionized water several times in order to remove the contaminants attached to the surface. Then the ribbon was applied to the next batch of degradation experiments and recycled several times until the ribbons lost its degradability. According to the statistics of the current research results (Table 4), Fe-MGs can be reused more than 4 times. The main reasons for the decrease of the catalytic performance of the materials include the following two points: (1) in the process of reductive degradation, a large number of reaction products precipitate many times on the surface of the catalyst, which hinders the diffusion of pollutants to the reaction interface. (2) The repeated contact between Fe-MGs and active substance $\cdot \mathrm{OH}$ in fenton reaction leads to serious surface oxidation of the catalyst [70]. Therefore, the reuse of $\mathrm{H}_{2} \mathrm{O}_{2}$ can be improved by controlling the amount of Fe-MGs, ultrasonic vibration and self-updating [53]. 
Table 4: Reuse of Fe-MGs in different wastewater

\begin{tabular}{|c|c|c|c|c|c|}
\hline MGs & $\begin{array}{l}\text { Preparation } \\
\text { method }\end{array}$ & Pollutant & $\begin{array}{l}\text { Degradation } \\
\text { mechanism }\end{array}$ & Reuse & Reference \\
\hline $\mathrm{Fe}_{78} \mathrm{Si}_{8} \mathrm{~B}_{14}{ }^{\mathrm{AR}}$ & $\begin{array}{l}\text { Melt } \\
\text { spinning }\end{array}$ & $\begin{array}{l}\text { Acid orange } \\
\text { II }\end{array}$ & $\begin{array}{l}\text { Hydrogenation } \\
\text { reduction }\end{array}$ & $\begin{array}{l}\text { The } k_{\text {obs }} \text { of the fourth time of } \\
\text { recycling is similar to that of } \\
\text { the first three times. }\end{array}$ & [57] \\
\hline $\mathrm{Fe}_{78} \mathrm{Si}_{9} \mathrm{~B}_{13}{ }^{\mathrm{AR}}$ & $\begin{array}{l}\text { Melt } \\
\text { spinning }\end{array}$ & $\begin{array}{l}\text { Rhodamine } \\
\text { B }\end{array}$ & $\begin{array}{l}\text { Fenton } \\
\text { oxidation }\end{array}$ & $\begin{array}{l}\text { After } 4 \text { times of recycling, } \\
\text { Rhodamine B can still be } \\
\text { completely degraded within } \\
10 \text { min. }\end{array}$ & [69] \\
\hline $\mathrm{Fe}_{78} \mathrm{Si}_{9} \mathrm{~B}_{13}{ }^{\mathrm{AR}}$ & $\begin{array}{l}\text { Melt } \\
\text { spinning }\end{array}$ & $\begin{array}{l}\text { Brilliant red } \\
\text { 3B-A }\end{array}$ & $\begin{array}{l}\text { Fenton } \\
\text { oxidation }\end{array}$ & $\begin{array}{l}\text { The decolorization rate of the } \\
\text { fourth recycling is } 70 \% \text { of that } \\
\text { of the first. }\end{array}$ & [49] \\
\hline $\mathrm{Fe}_{78} \mathrm{Si}_{9} \mathrm{~B}_{13}{ }^{\mathrm{AR}}$ & $\begin{array}{l}\text { Melt } \\
\text { spinning }\end{array}$ & $\begin{array}{l}\text { Naphthol } \\
\text { green B }\end{array}$ & $\begin{array}{l}\text { Fenton } \\
\text { oxidation }\end{array}$ & $\begin{array}{l}\text { It is reused } 10 \text { times and the } \\
\text { decolorization rate is } 89.4 \% \text {. }\end{array}$ & [73] \\
\hline $\mathrm{Fe}_{76} \mathrm{~B}_{12} \mathrm{Si}_{9} \mathrm{Y}_{3}{ }^{\mathrm{AR}}$ & $\begin{array}{l}\text { Melt } \\
\text { spinning }\end{array}$ & $\begin{array}{l}\text { Methyl } \\
\text { orange }\end{array}$ & $\begin{array}{l}\text { Hydrogenation } \\
\text { reduction }\end{array}$ & $\begin{array}{l}\text { The degradation rate remains } \\
\text { almost unchanged after } \\
\text { recycling for } 13 \text { times. }\end{array}$ & [42] \\
\hline $\mathrm{Fe}_{78} \mathrm{Si}_{9} \mathrm{~B}_{13}{ }^{\mathrm{AR}}$ & $\begin{array}{l}\text { Melt } \\
\text { spinning }\end{array}$ & $\begin{array}{l}\text { Methylene } \\
\text { blue }\end{array}$ & $\begin{array}{l}\text { Fenton } \\
\text { oxidation }\end{array}$ & $\begin{array}{l}\text { After } 20 \text { times of recycling, the } \\
\text { kobs decreased from } 0.718 \\
\min ^{-1} \text { to } 0.217 \text { min }^{-1} \text {, which is } \\
\text { still much higher than using } \\
\text { persulfate alone. }\end{array}$ & [52] \\
\hline $\mathrm{Fe}_{80} \mathrm{P}_{13} \mathrm{C}_{7}{ }^{\mathrm{AR}}$ & $\begin{array}{l}\text { Melt } \\
\text { spinning }\end{array}$ & $\begin{array}{l}\text { Methylene } \\
\text { blue }\end{array}$ & $\begin{array}{l}\text { Fenton } \\
\text { oxidation }\end{array}$ & $\begin{array}{l}\text { The loose cottonlike product } \\
\text { layer falls off from the strip, } \\
\text { exposing a fresh substrate. Can } \\
\text { be reused } 19 \text { times. }\end{array}$ & [53] \\
\hline
\end{tabular}

\section{Conclusion and Prospect}

In this paper, the research progress on the functional application of a new environmental functional material Fe-MGs in the treatment of wastewater polluted by organic compounds and heavy metals is reviewed. At present, the most widely studied is the catalytic degradation of azo dye wastewater. The main chemical reactions in the treatment process include decolorization, mineralization, and ion leaching. According to the different electron transfer modes of Fe-MGs, there are two degradation mechanisms. One is that Fe-MGs transfers electrons directly to pollutants for reductive degradation. The other is that Fe-MGs transfers electrons to peroxides to form a strong oxidizing active substance $\cdot \mathrm{OH}$, which is degraded by oxidation mechanism. A large number of comparative experimental results show that the $\mathrm{k}_{\mathrm{obs}}$ and degradation rate of pollutants treated by Fe-MGs are higher than those of traditional degrader ZVI. This is due to the fact that Fe-MGs have lower apparent activation energy and redox potential than ZVI. Secondly, the downward shift of the valence band top of Fe-MGs makes it easier for electrons to be excited to participate in chemical reactions. By observing the structure of the product layer of the two materials, it is found that the product layer of Fe-MGs have a three-dimensional nano-pore structure and is easy to fall off, which is beneficial to the electron transfer and the diffusion of pollutants to the reaction interface. Although MGs have many excellent properties, there are still some problems in the practical 
application of MGs as environmental functional materials in water treatment. For example, the current research mainly focuses on the degradation of a single azo dye, and the results are different from the actual situation. Even under the simplified experimental conditions, the theoretical research is still in the stage of fitting the kinetic and thermodynamic parameters, and the fundamental principle of how the amorphous structure causes the reduction of activation energy and redox potential and the acceleration of reaction rate constant is not clearly explained. In addition, the leaching of metal ions in the degradation process caused secondary pollution to the water. Based on the above problems, researchers should consider carrying out the following aspects of work in the future:

(1) Expand the application range of MGs in water treatment. MGs are mainly used to treat azo dye wastewater with single kinds of pollutants. Industrial wastewater is a coexistence system of many kinds of pollutants. Therefore, the effect of the interwoven system of heavy metals, toxic metals, and organic compounds on the degradation performance should be considered in the experimental stage.

(2) Preparation of amorphous composite materials. MGs can control the properties of alloys by changing the type and proportion of atoms, and can also consider the addition of strong conductive materials such as graphene, carbon nanotubes, and biochar to change the electronic conductivity.

(3) Further improve the theoretical system. The theoretical explanation for the high reactivity of MGs is still at the apparent level, so there is an urgent need to establish the model theory of electron transport behavior and amorphous structure in metastable state, so as to provide theoretical guidance for the design, development and performance improvement of MGs.

(4) Develop simulation software. Deeply understand the corrosion mechanism of MGs and optimize the design of MGs.

Acknowledgement: This work was supported by the National Natural Science Foundation of China (NSFC) [Grant Nos. 51661015 and 52061024]; and the Natural Science Foundation of Zhejiang Province [Grant No. LQ20E010002].

Funding Statement: This research was funded by the National Natural Science Foundation of China (NSFC) [Grant Nos. 51661015 and 52061024]; and the Natural Science Foundation of Zhejiang Province [Grant No. LQ20E010002].

Conflicts of Interest: The authors declare that they have no conflicts of interest to report regarding the present study.

\section{References}

1. Zhang, X., Huang, Q., Deng, F., Huang, H., Wan, Q. et al. (2017). Mussel-inspired fabrication of functional materials and their environmental applications: Progress and prospects. Applied Materials Today, 7, 222-238. DOI 10.1016/j.apmt.2017.04.001.

2. Zhao, D. H., Huang, L. M., Lin, X. N., Ran, L. H., Cai, W. W. et al. (2014). Research advance for applications of environmental functional materials in cationic dye wastewater treatment. Chemistry \& Bioengineering, 31(7), 1-4. DOI 10.3969/j.issn.1672-5425.2014.07001.

3. Tong, X., Wang, G., Stachurski, Z., Bednarík, J., Mattern, N. et al. (2016). Structural evolution and strength change of a metallic glass at different temperatures. Scientific Reports, 6, 386-474. DOI 10.1038/srep30876.

4. Inoue, A., Nishiyama, N. (2007). New bulk metallic glasses for applications as magnetic-sensing, chemical, and structural materials. MRS Bulletin, 32(8), 651-658. DOI 10.1557/mrs2007.128.

5. Cho, J. S., Jang, W., Park, K. H., Wang, D. H. (2020). Metallic amorphous alloy for long-term stable electrodes in organic sensors and photovoltaics. Organic Electronics, 84, 105811. DOI 10.1016/j.orgel.2020.105811. 
6. Baiker, A. (1990). Metallic glasses in heterogeneous catalysis. ChemInform, 21(30), 239-251. DOI 10.1002/ chin.199030339.

7. Si, J., Gu, J., Luan, H., Yao, K. (2020). Porous composite architecture bestows Fe-based glassy alloy with high and ultra-durable degradation activity in decomposing azo dye. Journal of Hazardous Materials, 388, 122043. DOI 10.1016/j.jhazmat.2020.122043.

8. Sun, H., Zheng, H., Yang, X. (2021). Efficient degradation of orange II dye using Fe-based metallic glass powders prepared by commercial raw materials. Intermetallics, 129, 107030. DOI 10.1016/j.intermet.2020.107030.

9. Koirala, I. (2018). Effects of surface coordination of atoms on the surface properties of $\mathrm{Cd}-\mathrm{x}(\mathrm{X}=\mathrm{Ga}, \mathrm{Zn})$ liquid alloys. Himalayan Journal of Science and Technology, 2, 90-95. DOI 10.3126/hijost.v2i0.25851.

10. Fan, J. J., Kou, S. Z., Ding, R. X., Jiang, Y. (2021). Process parameters study on structure and properties of Zrbased bulk metallic glasses. Materials Science Forum, 1035, 668-679. DOI 10.4028/www.scientific.net/ MSF.1035.668.

11. Jia, Z., Duan, X., Qin, P., Zhang, W., Wang, W. et al. (2017). Disordered atomic packing structure of metallic glass: Toward ultrafast hydroxyl radicals production rate and strong electron transfer ability in catalytic performance. Advanced Functional Materials, 27(38), 1702254. DOI 10.1002/adfm.201702258.

12. Wang, P., Wang, J. Q., Li, H., Yang, H., Huo, J. et al. (2017). Fast decolorization of azo dyes in both alkaline and acidic solutions by Al-based metallic glasses. Journal of Alloys and Compounds, 701, 759-767. DOI 10.1016/j. jallcom.2017.01.168.

13. Zhao, Y., Zhang, Q., Tang, B., Wang, H., Yao, Q. et al. (2019). Investigation on photocatalytic degradation properties of $\mathrm{Mg}_{69} \mathrm{Ni}_{15} \mathrm{Gd}_{10} \mathrm{Ag}_{6}$ amorphous alloy to wards methyl violet. Journal of Taiyuan University of Technology, 50(5), 556-561. DOI 10.16355/j.cnki.issn1007-9432tyut.2019.05.002.

14. Yang, X., Xu, X., Xiang, Q., Qu, Y., Ren, Y. et al. (2021). The catalytic performance of $\mathrm{Cu}_{46} \mathrm{Zr}_{47-\mathrm{x}} \mathrm{Al}_{7} \mathrm{Y}_{\mathrm{x}}$ amorphous ribbons in the degradation of AO II dye wastewater. Environmental Science and Pollution Research, 70, 1-15. DOI 10.1007/s11356-021-14102-2.

15. Shi, J., Ni, B., Zhang, J., Wu, C., Zhao, Z. (2019). Effect of Ni addition on catalytic performance of $\mathrm{Fe}_{87} \mathrm{Si}_{5} \mathrm{~B}_{2} \mathrm{P}_{3} \mathrm{Nb}_{2} \mathrm{Cu}_{1}$ amorphous alloys for degrading methylene blue dyes. Metals-Open Access Metallurgy Journal, 9(3), 341. DOI 10.3390/met9030341.

16. Klement, W. K., Willens, R. H., Duwez, P. (1960). Non-crystalline structure in solidified gold-silicon alloys. Nature, 187(4740), 869-870. DOI 10.1038/187869b0.

17. Chen, P., Hu, X. M., Qi, Y. M., Xin, W., Li, Z. et al. (2017). Rapid degradation of azo dyes by melt-spun Mg-Zn-Ca metallic glass in artificial seawater. Metals, 7(11), 485. DOI 10.3390/met7110485.

18. Louvier, R., Lopez, R. A., Fernandez, F. T., Urban, P., Cuevas, F. G. et al. (2021). Structure and size distribution of powders produced from melt-spun Fe-Si-B ribbons. Key Engineering Materials, 876, 25-30. DOI 10.4028/www. scientific.net/KEM.876.25.

19. Kumaoka, H., Hasegawa, A., Mori, S., Horino, K., Matsumoto, H. (2020). Fe-B-Nb-P nanocrystalline alloy with high amorphous forming ability for fabricating the powder. IEEE Transactions on Magnetics, 56(4), 1-4. DOI 10.1109/TMAG.2019.2962036.

20. Liu, K., Wang, S., Feng, Y., Zhang, K., Zhang, Y. (2020). Phase transformation mechanism and magnetic properties of Sm-Fe alloys produced by melt-spinning and high-energy ball milling. Journal of Magnetism and Magnetic Materials, 513, 167229. DOI 10.1016/j.jmmm.2020.167229.

21. Wu, Y., Zhang, L., Chen, S., Wei, L., Zhang, H. F. (2019). A multiple twin-roller casting technique for producing metallic glass and metallic glass composite strips. Materials, 12(23), 3842. DOI 10.3390/ma12233842.

22. Hin, S., Bernard, C., Doquet, V., Yokoyama, Y., Magueresse, A. et al. (2019). Bulk metallic glass. Materials Science \& Engineering A, 740, 137-147. DOI 10.1016/j.msea.2018.10.061.

23. Si, C., Zhang, Z., Zhang, Q. (2021). Influence of mechanical alloying on the particle size, microstructure and soft magnetic properties of coarse Fe-based amorphous powders prepared by gas atomization. Journal of NonCrystalline Solids, 559, 120675. DOI 10.1016/j.jnoncrysol.2021.120675. 
24. Ernst, A. T., Kerns, P., Nardi, A. T., Brody, H., Aindow, D. M. (2020). Surface states of gas-atomized al6061 powders-effects of heat treatment. Applied Surface Science, 534, 147643. DOI 10.1016/j. apsusc.2020.147643.

25. Chang, L., Xie, L., Liu, M., Li, Q., Dong, Y. et al. (2018). Novel Fe-based nanocrystalline powder cores with excellent magnetic properties produced using gas-atomized powder. Journal of Magnetism \& Magnetic Materials, 452, 442-446. DOI 10.1016/j.jmmm.2017.12.049.

26. Msetra, Z., Khitouni, N., Sunnol, J. J., Khitouni, M., Chemingui, M. (2021). Characterization and thermal analysis of new amorphous $\mathrm{Co}_{60} \mathrm{Fe}_{18} \mathrm{Ta}_{8} \mathrm{~B}_{14}$ alloy produced by mechanical alloying. Materials Letters, 292(1), 425-428. DOI 10.1016/j.matlet.2021.129532.

27. Shkodich, N. F., Vadchenko, S. G., Nepapushev, A. A., Kovalev, D. Y., Kovalev, I. D. et al. (2018). Crystallization of amorphous $\mathrm{Cu}_{50} \mathrm{Ti}_{50}$ alloy prepared by high-energy ball milling. Journal of Alloys and Compounds, 741, 575579. DOI 10.1016/j.jallcom.2018.01.062.

28. Nouri, Z., Sedighi, M. (2019). Microstructure and mechanical properties of powder thixoforged amorphous $\mathrm{Ni}_{55} \mathrm{Nb}_{35} \mathrm{Si}_{10}$-reinforced $\mathrm{Al}$ matrix composites. Journal of Materials Engineering and Performance, 28, $1151-$ 1160. DOI 10.1007/s11665-018-3829-1.

29. Surreddi, K. B., Scudino, S., Sakaliyska, M., Prashanthb, K. G., Sordeletc, D. J. et al. (2010). Crystallization behavior and consolidation of gas-atomized $\mathrm{Al}_{84} \mathrm{Gd}_{6} \mathrm{Ni}_{7} \mathrm{Co}_{3}$ glassy powder. Journal of Alloys and Compounds, 491(1-2), 137-142. DOI 10.1016/j.jallcom.2009.10.178.

30. Zhang, M., Zhang, Z. (2020). Numerical simulation study on cooling of metal droplet in atomizing gas. Materials Today Communications, 25, 101423. DOI 10.1016/j.mtcomm.2020.101423.

31. Si, C., Zhang, Z., Zhang, Q., Cai, J. (2021). Influence of mechanical alloying on the particle size, microstructure and soft magnetic properties of coarse Fe-based amorphous powders prepared by gas atomization. Journal of NonCrystalline Solids, 559, 120675. DOI 10.1016/j.jnoncrysol.2021.120675.

32. Ge, Y., Chen, X., Chang, Z. (2020). The forming and crystallization behaviors of $\mathrm{Zr}_{50} \mathrm{Ti}_{5} \mathrm{Cu}_{27} \mathrm{Ni}_{10} \mathrm{Al}_{8}$ bulk amorphous alloy by laser additive manufacturing. Materials Express, 10(7), 1155-1160. DOI 10.1166/ mex.2020.1724.

33. Yuan, H., Huo, W., Hao, Y., Wang, Y., Qiao, W. et al. (2020). Hydrogen generation from hydrolysis of sodium borohydride using nanosized $\mathrm{NiB}$ amorphous alloy catalysts. Nano, 15(6), 16077. DOI 10.1142/ S1793292020500812.

34. Chen, Z. L., Dong, Y. C., Wang, P., Cui, G., Li, B. (2016). Preparation of nano- $\mathrm{TiO}_{2} / \mathrm{SiO}_{2}$-loaded cotton fabrics and its photocatalytic performance for dyes degradation. Materials Reports, 30(14), 34-38. DOI 10.11896/j. issn.1005-023X.2016.14.008.

35. Pu, S., He, L., Liu, S. (2019). Review on the preparation of biochar composites and its applications in wastewater treatment. Industrial Water Treatment, 39(9), 1-7. DOI 10.11894/iwt.2019-0390.

36. Wang, Y. Z., Chen, M. X., Hu, C., Wang, J. (2000). A study of dye degradation in the combination process of photocatalytic oxidation with biochemical oxidation. Acta Entiae Circumstantiae, 2000(6), 772-775. DOI 10.3321/j.issn:0253-2468.2000.06.022.

37. Ke, G., Zhu, K., Chohowdhury, M. H. (2019). Dyeing of cochineal natural dye on cotton fabrics treated with oxidant and chitosan. Journal of Natural Fibers, 1(1), 1-13. DOI 10.1080/15440478.2019.1623742.

38. Jia, Z., Wang, Q., Sun, L., Wang, Q., Zhang, L. C. et al. (2019). Attractive in situ self-reconstructed hierarchical gradient structure of metallic glass for high efficiency and remarkable stability in catalytic performance. Advanced Functional Materials, 29(19), 1-9. DOI 10.1002/adfm.201807857.

39. Xie, S., Huang, P., Kruzic, J. J., Zeng, X., Qian, H. (2016). A highly efficient degradation mechanism of methyl orange using Fe-based metallic glass powders. DNA Repair, 6, 21947. DOI 10.1038/srep21947.

40. Wu, Y., Peng, K. (2018). Impact of ion bombardment on the structure and magnetic properties of $\mathrm{Fe}_{78} \mathrm{Si}_{13} \mathrm{~B}_{9}$ amorphous alloy. Journal of the Minerals, Metals \& Materials Society, 70(6), 861-865. DOI 10.1007/s11837-018-2827-y.

41. Zhang, C., Zhu, Z., Zhang, H., Hu, Z. (2012). On the decolorization property of Fe-Mo-Si-B alloys with different structures. Journal of Non-Crystalline Solids, 358(1), 61-64. DOI 10.1016/j.jnoncrysol.2011.08.023. 
42. Wang, Q., Chen, M., Lin, P., Cui, Z., Chu, C. L. et al. (2018). Investigation of FePC amorphous alloys with selfrenewing behaviour for highly efficient decolorization of methylene blue. Journal of Materials Chemistry A, 6(23), 10686-10699. DOI 10.1039/C8TA01534A.

43. Zeng, D., Dan, Z., Qin, F., Hui, C. A. (2019). Adsorption-enhanced reductive degradation of methyl orange by $\mathrm{Fe}_{73.3} \mathrm{Co}_{10} \mathrm{Si}_{4} \mathrm{~B}_{8} \mathrm{P}_{4} \mathrm{Cu}_{0.7}$ amorphous alloys. Materials Chemistry and Physics, 242, 122307. DOI 10.1016/j. matchemphys.2019.122307.

44. Deng, Z., Zhang, X. H., Chan, K. C., Liu, L., Li, T. (2017). Fe-based metallic glass catalyst with nanoporous surface for azo dye degradation. Chemosphere, 174, 76. DOI 10.1016/j.chemosphere.2017.01.094.

45. Zhang, C., Wang, Y., Zhang, X., Guo, H. (2020). $\mathrm{Fe}_{78} \mathrm{Si}_{9} \mathrm{~B}_{13}$ amorphous alloys for the decolorization process of azo dye aqueous solutions with different initial concentrations at different reaction temperatures. Vacuum, 176, 109301. DOI 10.1016/j.vacuum.2020.109301.

46. Qin, X., Li, Z., Zhu, Z., Fu, H. M., Li, H. et al. (2017). Mechanism and kinetics of treatment of acid orange II by aged Fe-Si-B metallic glass powders. Journal of Materials Science \& Technology, 33(10), 1147-1152. DOI 10.1016/j.jmst.2017.01.024.

47. Ji, L., Peng, S., Zheng, Z., Zuo, J., Yu, H. (2019). The degradation performance of the $\mathrm{Fe}_{78} \mathrm{Si}_{13} \mathrm{~B}_{9}$ and $(\mathrm{FeCoNi})_{78} \mathrm{Si}_{13} \mathrm{~B}_{9}$ high-entropy amorphous alloy ribbons. Journal of Alloys and Compounds, 815, 152347. DOI 10.1016/j.jallcom.2019.152347.

48. Chen, J. W., Ji, L., Zheng, Z. G., Liu, X., Qiu, Z. G. et al. (2021). Improving the degradation efficiency for the azo dye of $\mathrm{Fe}_{82} \mathrm{Si}_{2.5} \mathrm{~B}_{12} \mathrm{P}_{2.5} \mathrm{C}$ alloy via heat treatment. Materials Letters, 300, 130187. DOI 10.1016/j. matlet.2021.130187.

49. Jia, Z., Liang, S. X., Zhang, W. C., Wang, W. M., Zhang, L. C. (2017). Heterogeneous photo fenton-like degradation of cibacron brilliant red 3B-A dye using amorphous $\mathrm{Fe}_{78} \mathrm{Si}_{9} \mathrm{~B}_{13}$ and $\mathrm{Fe}_{73.5} \mathrm{Si}_{13.5} \mathrm{~B}_{9} \mathrm{Cu}_{1} \mathrm{Nb}_{3}$ alloys: The influence of adsorption. Journal of the Taiwan Institute of Chemical Engineers, 71, 128-136. DOI 10.1016/j.jtice.2016.11.021.

50. Jia, Z., Li, X. F., Liang, S. X., Qin, P., Habibi, D. et al. (2017). Rapid decolorization and mineralization of Congo red using $\mathrm{Fe}_{78} \mathrm{Si}_{9} \mathrm{~B}_{13}$ amorphous alloy by photo fenton-like process. Materials in Environmental Engineering, 23, 765-776. DOI 10.1515/9783110516623-075.

51. Liang, S., Jia, Z., Zhang, W., Wang, W. M., Zhang, L. C. (2017). Rapid malachite green degradation using $\mathrm{Fe}_{73.5} \mathrm{Si}_{13.5} \mathrm{~B}_{9} \mathrm{Cu}_{1} \mathrm{Nb}_{3}$ metallic glass for activation of persulfate under UV-vislight. Materials \& Design, 119, 244-253. DOI 10.1016/j.matdes.2017.01.039.

52. Jia, Z., Duan, X., Zhang, W. C., Wang, W., Sun, H. et al. (2018). Ultra-sustainable $\mathrm{Fe}_{78} \mathrm{Si}_{9} \mathrm{~B}_{13}$ metallic glass as a catalyst for activation of persulfate on methyleneblue degradation under UV-vis light. Journal of Materials Chemistry A, 6(23), 10686-10699. DOI 10.1038/srep38520.

53. Wang, Q., Chen, M., Lin, P., Cui, Z., Chu, C. L. et al. (2016). Investigation of FePC amorphous alloys with selfrenewing behaviour for highly efficient decolorization of methylene blue. Scientific Reports, 6, 38520. DOI 10.1039/C8TA01534A.

54. Yan, Y., Liang, X., Ma, J., Shen, J. (2020). Rapid removal of copper from wastewater by Fe-based amorphous alloy. Intermetallics, 124, 106849. DOI 10.1016/j.intermet.2020.106849.

55. Zhang, X., Liu, J., Li, J., Li, C., Yuan, Z. (2020). Excellent capability in remediating $\mathrm{Cu}^{2+}$ from aqueous solution by Fe-Si-B amorphous alloys. Applied Physics A, 126(4), 291. DOI 10.1007/s00339-020-3465-0.

56. Liang, S. X., Zhang, W., Zhang, L., Wang, W., Zhang, L. C. (2019). Remediation of industrial contaminated water with arsenic and nitrate by mass-produced Fe-based metallic glass: Toward potential industrial applications. Sustainable Materials and Technologies, 22, 00126. DOI 10.1016/j.susmat.2019.e00126.

57. Zhang, C., Zhu, Z., Zhang, H., Hu, Z. (2012). Rapid decolorization of acid orange II aqueous solution by amorphous zero-valent iron. Journal of Environmental Science, 24(6), 1021-1026. DOI 10.1016/S1001-0742 (11)60894-2.

58. Tang, Y., Shao, Y., Chen, N., Yao, K. F. (2015). Rapid decomposition of direct blue 6 in neutral solution by Fe-B amorphous alloys. RSC Advances, 5(8), 6215-6221. DOI 10.1039/c4ra10000j. 
59. Tang, Y., Shao, Y., Chen, N., Yao, K. F. (2015). Insight into the high reactivity of commercial Fe-Si-B amorphous zero-valent iron in degrading azo dye solutions. RSC Advances, 5(43), 34032-34039. DOI 10.1039/ C5RA02870A.

60. Tang, Y. (2015). Synthesis and azo dye degradation properties of iron-based amorphous alloys. Beijing: Tsinghua University.

61. Hu, Z. Z. (2012). Rapid decolorization of acid orange II aqueous solution by amorphous zero-valent iron. Journal of Environmental Sciences, 24(6), 1021-1026. DOI 10.1016/S1001-0742(11)60894-2.

62. Zhang, C., Zhu, Z., Zhang, H., Hu, Z. (2012). On the decolorization property of Fe-Mo-Si-B alloys with different structures. Journal of Non-Crystalline Solids, 358(1), 61-64. DOI 10.1016/j.jnoncrysol.2011.08.023.

63. Yang, W., Wang, Q., Li, W., Xue, L., Shen, B. (2019). A novel thermal-tuning Fe-based amorphous alloy for automatically recycled methylene blue degradation. Materials \& Design, 118, 136-146. DOI 10.1016/j. matdes.2018.11.031.

64. Weng, N., Wang, F., Qin, F. X., Tang, W., Dan, Z. (2017). Enhanced azo-dyes degradation performance of Fe-Si-BP nanoporous architecture. Materials, 10(9), 1001. DOI 10.3390/ma10091001.

65. Zhang, C. Q., Zhu, H. F., Zhang, Z. W. (2017). Effects of the addition of Co, Ni or $\mathrm{Cr}$ on the decolorization properties of Fe-Si-B amorphous alloys. The Journal of Physics and Chemistry of Solids, 110, 152-160. DOI 10.1016/j.jpcs.2017.06.010.

66. Zhang, C. Q., Zhu, Z. W., Zhang, H. F., Hu, Z. Q. (2011). Rapid reductive degradation of azo dyes by a unique structure of amorphous alloys. Chinese Science Bulletin, 56(36), 3988. DOI 10.1007/s11434-011-4781-8.

67. Brtan, H., Pakman, Y., Chien, C. H., Chu, J. P. (2021). Fe-based thin film metallic glass as an activator of peroxymonosulfate for azo dye degradation. Surface and Coatings Technology, 421, 127031. DOI 10.1016/j. surfcoat.2021.127031.

68. Chen, S. Q., Li, M., Ma, X. Y., Zhou, M. J., Yao, K. F. (2021). Influence of inorganic ions on degradation capability of Fe-based metallic glass towards dyeing wastewater remediation. Chemosphere, 264(1), 128392. DOI 10.1016/j. chemosphere.2020.128392.

69. Wang, X., Pan, Y., Zhu, Z., Wu, J. (2014). Efficient degradation of rhodamine B using Fe-based metallic glass catalyst by fenton-like process. Chemosphere, 117, 638-643. DOI 10.1016/j.chemosphere.2014.09.055.

70. Jia, Z., Zhang, W. C., Wang, W. M., Habibi, D., Zhang, L. C. (2016). Amorphous $\mathrm{Fe}_{78} \mathrm{Si}_{9} \mathrm{~B}_{13}$ alloy: An efficient and reusable photo-enhanced fenton-like catalyst in degradation of cibacron brilliant red 3B-A dye under UV-vis light. Applied Catalysis B Environmental, 192, 46-56. DOI 10.1016/j.apcatb.2016.03.048.

71. Jia, Z., Kang, J., Zhang, W. C., Wang, W. M., Yang, C. et al. (2017). Surface aging behaviour of Fe-based amorphous alloys as catalysts during heterogeneous photo fenton-like process for water treatment. Applied Catalysis B: Environmental, 204, 537-547. DOI 10.1016/j.apcatb.2016.12.001.

72. Yang, J. F., Bian, X. F., Mei, L. (2013). Excellent degradation performance of azo dye by metallic glass/titanium dioxide composite powders. Journal of Sol-Gel Science and Technology, 67(2), 362-367. DOI 10.1007/s10971013-3089-3.

73. Li, X. F., Liang, S. X., Xi, X. W., Zhe, J., Xie, S. K. et al. (2017). Excellent performance of $\mathrm{Fe}_{78} \mathrm{Si}_{9} \mathrm{~B}_{13}$ metallic glass for activating peroxymonosulfate indegradation of naphthol green B. Metals, 7(7), 273. DOI 10.3390/ met7070273. 